\title{
Modern Kredi Sınıflandırma Çalışmaları ve Metasezgisel Algoritma Uygulamaları: Sistematik Bir Derleme*
}

\author{
Hazar Altınbaş1 10
}

Öz

Kredi başvurularında, başvuranların temerrüde düşüp düşmeyeceklerinin başarılı şekilde tahmin edilmesi amacıyla önerilen gelişmiş analiz yöntemlerinin sayısı, özellikle Küresel Finans Krizi sonrası dönemde önemli bir artş̧ göstermiştir. Geleneksel istatistiksel sınıflandırma yöntemlerine alternatif olarak bilgiyi, kısıtlar ve varsayımlardan bağımsız olarak doğrudan veri kümelerinden ortaya çıkarma yeteneğine sahip makine öğrenme yöntemleri kullanılmaya başlanmıştı. Bu yöntemlerin yanı sıra, sınıflandırma performansları üzerinde çok büyük iyileştirmeler sağlayan metasezgisel algoritmalar da yazında kendilerine fazlaca yer bulmaya başlamıştır. Veri saklama ve işleme kapasitelerinde yaşanan artş̧tan en üst düzeyde faydalanmaya yönelik olarak öğrenme yöntemleri ile metasezgisel algoritmaların birlikte kullanımları, kredi risk değerlendirme alanına büyük katkılar sağlamaktadır. Bu derleme kapsamında 2000 sonrası dönemde yazına sunulmuş olan ve metasezgisel algoritmaların yer aldığı kredi sınıflandırma çalışmaları sistematik bir süreç ile incelenmiştir. Yazında karşılaşılan sınıflandırma yöntemleri, uygulanan metasezgisel algoritmalar ile kullanım amaçları ve sınıflandırma performans değerlendirme kriterleri ele alınmış ve mevcut duruma ilişkin genel bir çerçeve oluşturulmuştur. İnceleme, metasezgisel algoritmalar ile makine öğrenme yöntemlerine yönelik artan bir ilgi olduğunu ortaya koymaktadır ancak yöntem tercihleri birkaç alternatif üzerine yoğunlaşmış durumdadır. Yeni geliştirilen metasezgisel algoritmaların ve/veya hibrit ve birlikte kullanımların alanda daha fazla yer alması gerekmektedir. Bilgisayar ve matematik bilimlerinde yaşanan gelişmeler ile paralel olarak ilerleyecek çalışmaların, yazına sürekli katkı sunmaya devam edeceğini söylemek mümkündür.

\section{Anahtar Kelimeler}

Kredi riski, Kredi skoru, Kredi değerlendirme, Makine öğrenme, Metasezgisel algoritmalar

\section{Metaheuristic Algorithms and Modern Credit Classification Methods: A Systematic Review}

\footnotetext{
Abstract

Number of proposed advanced analysis methods, which try to successfully predict if applicants are going to default in credit applications show an increasing pattern, especially after the Global Financial Crisis. Alternative to conventional statistical classification methods, machine learning methods arrive on the scene; they have capability to reveal information from the data independently from constraints and assumptions. Along with machine learning methods, metaheuristic algorithms that substantially improves classification performances take part in studies. Combined usages of learning methods and metaheuristic algorithms aim to benefit from the contemporary data storage and process capacities at the highest level and greatly contribute to credit risk assessment field. In this review study, credit classification studies that adopt metaheuristic algorithms in the analyses are examined with a systematic process, for the period after

* Çalışmanın her aşamasında fikir ve yorumlarıyla yol gösteren Gamze Gültekin ve Dr. Ayhan Bülent Toptaş'a; yerinde eleştirileri ve önerileri ile makalenin son halini almasında büyük katkıları olan Hakem'e teşekkürü borç bilirim.

1 Sorumlu Yazar: Hazar Altınbaş (Dr.), Bankacılık ve Finans Bölümü, Beykent Üniversitesi, İstanbul, Türkiye.

E-posta: altinbashazar@gmail.com ORCID: 0000-0001-8160-0611

Atıf: Altinbas, H. (2020). Modern kredi sınıflandırma çalışmaları ve metasezgisel algoritma uygulamaları: Sistematik bir derleme. Istanbul Business Research, 49(1), 146-175. http://doi.org/10.26650/ibr.2020.49.0033
} 
2000. By forming a general framework, classification methods, metaheuristic algorithm implementations, algorithms' intended uses and performance assessment criteria are addressed. Examination showed that there is a growing interest, nevertheless method preferences are concentrated over a limited option. It is necessary to incorporate more novel metaheuristics and/or hybrid and combined usages to the studies. It is possible to say that progressive works parallel to the developments in computer and mathematical sciences will continuously contribute to the literature.

Keywords

Credit risk, Credit scoring, Credit assessment, Machine learning, Metaheuristics algorithms

\section{Extended Summary}

Review Subject: This systematic review examines studies in credit risk assessment field, that apply metaheuristic algorithms for classification and optimization purposes. Objective of these algorithms is to improve performances of credit applicants' classifications as good or bad, which are predicted and interpreted as non-defaulters and defaulters, respectively.

Study Questions: The review aims to shed light on the examples of metaheuristic algorithms usages in credit classification analyses and exhibit a contemporary framework. In this sense, answers to the following four questions are searched:

1. What is the trend of metaheuristic algorithm applications over 2000-2018 period and which algorithms are used specifically?

2. What are the main classifiers in the analyses with metaheuristic optimization improvement?

3. How are the performances of analyses with metaheuristic improvements are evaluated?

4. What is the most recent situation in credit risk classification with metaheuristic optimization?

Methodology: Prisma systematic review process is followed. Articles found in Web of Science, Scopus and ProQuest databases are included. Reviews, conference proceedings, patents and theses are not included. Three group of keywords are used for searching:

Group 1: "credit scoring", "credit evaluation”, "credit assessment”, "credit risk assessment”, "credit decision";

Group 2: "classification", "data mining", "machine learning", "statistical learning", "soft computing", "computational intelligence";

Group 3: "metaheuristic", "evolutionary computing", "heuristic", "genetic algorithm", "genetic programming", "swarm intelligence", "evolutionary programming"

All included studies' objectives are either classification and/or improvement of classification performances. 
Results and Conclusions: By following the systematic process, a total of thirty articles are found over the examination period. Publishing trend shows at least one article is presented to the literature each year after 2005 and there is a strong positive trend after 2015. It seems like more and more researchers are attracted to make use of metaheuristic algorithms to optimize credit classification analyses. Studies report improved performances with metaheuristic algorithm utilizations.

Most metaheuristic algorithm designs are not suitable to classify observations in data sets. For this reason, they are used as an optimization technique rather than classifier itself. In the examined studies, only Genetic Programming is found to be used as both a classifier and optimization method, by virtue of its solution representation and solution space searching design. In credit risk assessment, as the first empirical studies used statistical learning methods like classical linear regression, logistic regression and discriminant analysis, machine learning and unsupervised methods became more popular in the last two decades. Neural network models, support vector machines, tree-based methods, Bayesian networks, fuzzy logic and k-nearest neighborhood models are preferred classifiers, while the former two are dominating the field.

Frequently used metaheuristic in the studies is Genetic Algorithm, which is also well-known in other research fields with intense data analysis. Genetic algorithm is followed by Genetic Programming, Particle Swarm Optimization, Tabu Search and Simulated Annealing. Choice of metaheuristic seem to be focused only on a few alternatives, though there are many other suggestions available in optimization literature.

Metaheuristics contribute to classifier performances in several ways. More widely, they are used for variable selection, to find optimum set of variables to teach the main classifier in the analyses. This selection provides classifier with a smaller set of variables and thus improve efficiency and effectivity. Parameter optimization comes after feature selection; in which several parameters of the classifiers are optimized. It is important to configure parameters in a proper way to achieve best results. Optimizing variables to be included and method parameters are both complex in nature, and best or near to best solution finding cannot be done by more conventional optimization techniques that aim to find exact solutions. Metaheuristics' main advantage is their solution space searching mechanisms and can provide feasible solutions in reasonable times. Therefore, implementation of metaheuristic search algorithms into analyses significantly contributes to credit risk assessments/scorings.

This review shows that a solid literature is formed for metaheuristic applications in credit classification. More and more studies are expected to be presented in the future. There lies a huge potential by widening the choice of algorithms and hybrid/combined forms. By following this pace, credit risk management activities in banks may continue to benefit from developments in data analysis field. 


\section{Modern Kredi Sınıflandırma Çalışmaları ve Metasezgisel Algoritma Uygulamaları: Sistematik Bir Derleme}

Bu çalışmada, temerrüt olasılıklarının belirlenmesinde kullanılan güncel yöntemlerde metasezgisel algoritma kullanımına ilişkin sistematik bir yazın taraması sunulmuştur. Amaç, her geçen gün artan sayıda veriyi kendi yargıları ya da yetersiz yöntemler ile analiz etmesi imkânsız olan karar vericilere destek olabilecek bir grup teknik ve yaklaşımın ortaya konması, katkılarının, avantaj ve dezavantajlarının karşılaştırılmalı olarak incelenmesidir. Aynı zamanda çalışmalarda kullanılan veri kümeleri ve benimsenen performans kriterleri ve doğrulama yaklaŞımları da araştırılmıştır. Böylelikle gelecekte yapılacak çalışmalara zemin oluşturacak çerçevenin doğru şekilde belirlenmesi de hedeflenmiştir.

Kredi risk değerlendirmesinde kullanılan yöntemlerin tarandığı yakın tarihli üç çalışma bulunmaktadır. Bunlardan Marqués, García ve Sánchez (2013)'in çalışması evrimsel hesaplama adı verilen ve evrimsel süreçlerden esinlenilerek ortaya çıkartılan hesaplama teknikleri üzerine yoğunlaşmıştır. Söz konusu hesaplama teknikleri metasezgisel algoritmalar kategorisi içerisinde yer almaktadır. Sistematik bir derleme çalışması yapan Louzada, Ara ve Fernandes (2016), klasik ve istatistiksel/makine sınıflandırma yöntemlerinden bahsetmiş olsalar da metasezgisel algoritma kullanım örneklerine kısaca değinmişlerdir. Benzer şekilde Chen, Ribeiro ve Chen (2016) tarafından yayınlanmış çalışmada da istatistiksel ve makine öğrenme teknikleri ve performans değerlendirmelerine ilişkin kapsamlı bir inceleme yapılmış olmasına rağmen yazında karşılaştıkları metasezgisel algoritmalardan yeterince bahsedilmemiştir.

Bu çalışmada, modern kredi değerlendirme çalışmalarında kullanılan yöntemler içerisinde metasezgisel algoritmaların yeri ve katkısı araştırılmıştır. Derlemenin ana motivasyonu, kurumların risk yönetim süreçlerini geliştirmelerini ve iyileştirmelerini sağlayacak gelişmiş yöntem önerilerine ilişkin güncel bir çerçeve sunmak ve ileride yapılacak çalışmalarda kullanılabilecek bütüncül bir temel ortaya koymaktır. Nitel analiz sonucu elde edilen bulgular dâhilinde çalışmalarda kullanılan yöntemler ve kullanım amaçları tanıtılmıştır. Ek olarak, yöntemler ile analiz edilen referans veri kümeleri, tercih edilen farklı analiz performans kriterleri ve önerilen yaklaşımların yeni gözlemlerin sınıflandırılmasına yönelik genelleme becerilerinin araştırıldığı doğrulama yöntemleri açıklanmıştır.

Takip eden bölümde, kredi sınıflandırmasında kullanılan yöntemlere ve metasezgisel algoritmalara ilişkin kısa tanıtımlar yapılmıştır. Yöntem bölümünde çalışmada benimsenmiş olan tarama yöntemi açıklanmıştır. Bulgular bölümünde kredi risk sınıflandırmasında metasezgisel algoritmalardan da yararlanılan çalışmalar sunulmuş, çalışmalarda benimsenmiş yaklaşımlar ve kullanılan araçlar tanıtılmıştır. Derleme, elde edilen bulguların genel bir değerlendirmesinin yapıldığg ve gelecek çalışmalara yönelik önerilerin aktarıldığı Tartışma ve sonuç bölümü ile son bulmaktadır. 


\section{Kredi sınıflandırmasında kullanılan yöntemler ve metasezgisel algoritmalar}

Kredi başvurularının kategorize edilmesinde temel sınıflandırıcı olarak kullanılan yöntemlerin çok büyük bir kısmı istatistiksel ve makine öğrenme yöntemleri olarak ikiye ayrılmaktadır. İstatistiksel öğrenme yöntemlerinde modeller oluşturulmakta, gözlem sınıflarının ve değişkenlerin olasılık dağılımları hakkında varsayımlarda bulunulmakta ve model parametreleri söz konusu varsayımlara bağlı olarak oluşturulmaktadır. Oluşturulan modeller belirli varsayımlar içerdiğinden, bu yöntemlerde hipotez testi yapmak ve anlamlılık sınamak mümkün olabilmektedir. Doğrusal regresyon (DR), lojistik regresyon (LR) ve doğrusal ayrıştırma analizi (DAA), kredi risk değerlendirmesindeki öncül çalışmalarda sıklıkla kullanılmış olan istatistiksel öğrenme yöntemleridir. Bilgisayarların işlem güçlerinde yaşanan artışa bağlı olarak bu yöntemler yerlerini makine öğrenme yöntemlerine bırakmışlardır. İstatistiksel öğrenme yöntemleri günümüzde daha çok yöntem performanslarının karşılaştırması amacıyla kullanılmaktadir.

Makine öğrenmede bir model kurulumu yapılmamaktadır. Bu yöntemler öğrenim sürecini, varsayımlardan bağımsız olarak veri kümesindeki örüntüleri ve ayrışmaları tespit ederek gerçekleştirir. Sinir ağları (SA), destek vektör makineleri (DVM), k-en yakın komşuluk (KYK), Bayes ağları (BA) ve ağaç tabanlı yöntemler (karar ağaçları, rasgele (rastgele) ormanlar vb.: AĞAÇ) kredi değerlendirme çalışmalarında kullanılan popüler makine öğrenme yöntemlerindendir. İstatistiksel ve makine öğrenme yöntemlerine ilişkin farklar Tablo 1'de özetlenmiştir.

İstatistiksel öğrenme yöntemleri kullanan analistler zorunlu olarak, bağımlı ve bağımsız değişkenler arasındaki ilişkiler ve istatistiksel özellikleri hakkında çoğu zaman, aşırı basitleştirilmiş ve gerçekçiliği tartışmaya açık varsayımlarda bulunurlar. Bu sebeple bu yöntemler karmaşık problemlerin modellenmesi konusunda zayıf kalabilmektedirler. İstatistiksel öğrenme yöntemlerinin en büyük avantajları, ilişki biçimlerinin önceden kurgulanmış olması, daha az bilgi işlem gücüne gereksinim duymaları ve aday çözümleri anlamlı süreler içerisinde ortaya koyabilmeleridir.

Tablo 1

Istatistiksel ve Makine Öğrenme Yöntemleri Karşılaştırması

\begin{tabular}{|c|c|c|}
\hline & İSTATISTIIKSEL ÖĞRENME & MAKINE ÖĞRENME \\
\hline Model kurulumu & Evet & Hayır \\
\hline $\begin{array}{c}\text { Değişkenler arası ilişkilerin biçimi hakkında } \\
\text { varsayım }\end{array}$ & Evet & Hayır \\
\hline Gözlemlerin dağılımı hakkında varsayım & Evet & Hayır \\
\hline Tahmin edilen parametre sayısı & Sinırlı & Sinırsiz \\
\hline Bilgisayar işlem gücü gereksinimi & $\begin{array}{l}\text { Gözlem sayısından bağımsız olarak } \\
\text { genelde kabul edilebilir seviyede }\end{array}$ & $\begin{array}{c}\text { Gözlem sayısına bağlı olarak } \\
\text { hızla artan }\end{array}$ \\
\hline
\end{tabular}


Makine öğrenme yöntemleri ise varsayım ve sınırlamalardan bağımsızdırlar. Bu yöntemler gözlem verilerini takip ederek ilişkiye ilişkin modellemeyi süreç içerisinde geliştirirler ve buna bağlı olarak da çok sayıda gözleme ve bilgi işleme kapasitesine ihtiyaç duyarlar. Ancak gözlem sayısı arttığında işlem süreleri de uzamakta ve zaman zaman kabul edilebilir sınırları aşabilmektedir.

Bu iki grup dışında bir de bulanık mantık (BM) adı verilen ve gözlem sınıflarının kesin olarak değil, belirsizliğe izin veren bir grup kurala (örneğin eğer-ise) göre hesaplanan üyelik fonksiyonları dâhilinde belirlendiği yöntemler bulunmaktadır. Bulanık mantık yaklaşımı, standart öğrenme yöntemlerinin farklı bileşenlerine uygulanarak belirsizliğin analizlere dâhil edilmesini sağlayabilmektedir. Örneğin ANFIS (adaptive neuro-fuzzy inference system) yönteminde SA topolojisi bulanık mantık ilkelerine bağlı olarak oluşturulur ${ }^{1}$.

Sonraki bölümlerde, bahsi geçen üç grupta yer alan ve kredi sınıflandırmasında kullanılan yöntemler ve metasezgisel algoritmalar kısaca tanıtılmıştır.

\section{İstatistiksel öğrenme yöntemleri}

Doğrusal regresyon. DR' de bağımsız değişkenler ile bağımlı değişken arasında doğrusal bir ilişki kurulur. Kredi değerlendirme çalışmalarında olduğu gibi gözlem sınıflarının tahmin edildiği durumlarda, belirli bir eşik değere göre sayısal tahminler sınıf kategorilerine (0 ve 1 olarak) dönüştürülür. Ancak elde edilen doğru ile bu değerlerin 0 ve 1 aralığının dışına taşmas1 da olasıdır. Bu sebeple tahmin değerleri birer olasılık olarak görülememektedir. DR 'nin sınıflandırma çalışmalarında kullanımının çok uygun olmadığını söylemek mümkündür.

Lojistik regresyon. LR, DR'ye benzer şekilde değişkenler arasındaki ilişkiyi bir eğri ile açıklamaktadır. DR çok büyük oranda bağımlı değişkenin sürekli sayısal değerler aldığı problemlerde kullanılır ve DR'de oluşturulan denklem ile elde edilen bilgi, bir gözlemi sınıflandırmak için elverişli değildir; bağımlı değişkenin hangi aralıklarında hangi sınıfın tahmin edileceği belirsizdir. İkiden fazla sınıf olması durumunda da sınıflar arasındaki farklar eşit sayılmakta ve tahmin sonuçları, kategorik sınıfların sayısal olarak kodlanma tercih ve sıralarına bağlı olarak ciddi ölçüde değişebilmektedir. LR'de ise böyle bir sorunla karşılaşılmaz: regresyon denklemi, lojistik fonksiyon ile [0-1] aralığında bir olasılık değerine dönüştürülür ve gözlemlerin ait olduğu sınıflar kullanıcı tarafından belirlenen olasılık eşik değerlerine bağlı olarak tahmin edilir. Sınıflandırma çalışmalarında oldukça kullanışlı olan LR, kredi sınıflandırma çalışmalarının hemen hepsinde ya temel sınıflandırıcı olarak ya da performans karşılaştırması amacıyla referans bir yöntem olarak kendisine yer bulmaktadır.

1 Makine öğrenme ve veri madenciliğinde bulanık mantık kullanımına ilişkin kapsamlı bir değerlendirme için Hüllermeier (2005)' in çalışmasına bakılabilir. 
Doğrusal ayrıştırma analizi. DAA'da tahmin değişkenlerinin her bir sınıf kategorisindeki dağılım parametreleri (normallik varsayımı altında) ayrı ayrı hesaplanır. Söz konusu parametrelere bağlı olarak da sınıfların birbirlerinden en iyi şekilde ayrılmasını sağlayan ve tahmin değişkenlerinin doğrusal bir kombinasyonu ile sınıf sayısına bağlı olarak bir ya da birden çok doğru oluşturulur. Bu doğru denklem(ler)i ile elde edilen ayrıştırma değer(ler)i, bir gözlemin sınıflara hangi olasılıklarla dâhil olduğunun belirlenmesinde kullanılır. DAA, kredi risk değerlendirmesi yazınındaki en eski çalışmalardan beri kullanılan ve günümüze kadar da popülaritesini korumuş yöntemlerin başında gelmekle birlikte derleme kapsamında sentezlenen çalışmalar içerisinde temel sınıflandırıcı olarak çok fazla yer almadığı görülmüştür. DAA da LR'ye benzer şekilde çalışmalarda genellikle performans karşılaştırması yapmak amacıyla yer almaktadır.

\section{Makine öğrenme yöntemleri}

Sinir ağlarl. SA, insan beyninin veriyi işleme ve öğrenme süreçlerinden esinlenerek tasarlanmış olan makine öğrenme yöntemleridir. Analojiye göre sisteme sunulan girdi değişkenleri, gizli katmanlarda bulunan nöronlar aracılı̆̆ıyla işlenir ve çıktı katmanında bulunan nöron(lar) ile nihai değere ulaşılır. Verinin işlenmesi, girdi değişkenlerinin doğrusal ve doğrusal olmayan etkileşimler ile birleştirilmesi ile gerçekleştirilir. Bir SA tasarımı içerisinde gizli katman sayısı, gizli katmanlarda bulunan nöron sayıları, nöronlara iletilen bilginin hesaplandığı toplama (birleştirme) fonksiyonu ve nöronların, kendilerine iletilen bilgiye bağl1 olarak üreteceği çıktı değerinin hesaplandığ 1 aktivasyon fonksiyonu SA'nın öğrenme ve genelleştirme yapma performansını doğrudan etkilemektedir. Uygun tasarımların kullanıcı tarafından belirlenmesi gerekir. SA, kredi değerlendirme çalışmalarında en çok tercih edilen yöntemlerden birisidir. Yöntemin kara kutu tabir edilen yapıda olması, girdiler ile çıktılar arasındaki ilişkinin yorumlanmasını zorlaştırmaktadır ve yöntemin en büyük eksikliğidir. Söz konusu eksiklik, ilişki kurallarının ortaya çıkartılmasına yönelik uygulanan ek yaklaşımlar ile giderilmeye çalışılmaktadır.

Destek vektör makineleri. Kredi değerlendirme çalışmalarında SA ile birlikte en çok tercih edilen ikinci yöntem DVM'dir. DVM'de sınıflandırma uzayında negatif (iyi sınıf) ve pozitif (kötü sınıf) gözlemlerin, oluşturulacak hiperdüzlemler ile optimum (en iyi) şekilde ayrıştırılması amaçlanır. Bir problemde oluşturulacak hiperdüzlem sayısı, sınıflandırma kararını belirleyen değişken sayısının bir eksiği kadar olur. Eğitim için kullanılan gözlemlerin hepsini doğru şekilde ayrıştırabilen bir hiperdüzlem, aşırı-öğrenme adı verilen ve genelleme yeteneğinin düşük olduğu olgunun ortaya çıkmasına sebep verebilmektedir. Bu sebeple DVM'de öğrenim sırasında bazı gözlemlerin yanlış sınıflandırılmasına izin veren bir marjin (sınır/kenar) doğrusu belirlenir. Böylelikle yöntemin, test kümelerindeki (bkz. Performans kriterleri ve doğrulama metotları bölümü) sınıflandırmalarda başarı oranının yükseltilmesi sağlanır. DVM ile yapılan ayrıştırma sırasında, girdi verilerinin dönüştürülmesini sağlayan çekirdek (kernel) 
fonksiyonları ile sağlanan yapay veriler kullanılmaktadır. Çekirdek fonksiyonlar ile değişkenler arasındaki yüksek korelasyonun olduğu ve/veya ilişkinin doğrusal olmadığı durumlar modellenebilmektedir. Doğrusal, polinomiyal ve radyal fonsksiyonlar, yazında sıkça karşılaşılan çekirdek fonksiyonlarıdır.

Ağaç tabanlı yöntemler. Karar kuralları ile sınıflandırma uzayında bölümleme yaparak en iyi sınıflandırma ayrıştırması yapmayı hedefleyen AĞAÇ, kredi risk değerlendirme çalışmalarında en çok tercih edilen üçüncü yöntem grubunu oluşturmaktadır. Tüm AĞAÇ yapıları, karar değişkenlerinin aldıkları değerler içerisinde ayrım noktaları belirler ve böylece oluşan bölgelerin içerisinde bir sınıfa ait maksimum sayıda gözlem kalmasını amaçlar. Hiyerarşik bir ağaç oluşumu sürecinde, tepede en iyi ayrışmayı sağlayan değişken seçilir. Her yeni bölge içerisinde, söz konusu değişken seçimi tekrar yapılır ve önceden belirlenmiş bir sonlandırma kriteri (her bölgede kalması gereken minimum gözlem sayısı ya da ağaç derinliği gibi) sağlanana kadar ayrıştırma devam eder. En basit AĞAÇ örneği olan karar ağaçları, yöntem basitliği ve oluşan ağacın kolay yorumlanabilmesi sebebiyle oldukça kullanışlı olsa da eğitim kümesinin aşırı-öğrenilmesi ve baskın bir değişkenin, ağacın tepe kesim noktasında yer alarak olası daha iyi çözümlerin araştırılmasını engelleyebilmesi gibi sorunlara maruz kalabilmektedir. Ağaç budaması, torbalama, rasgele ormanlar gibi yöntemler ile söz konusu problemlerin önüne geçmek mümkün olabilmektedir. Ayrıca, bölümleme kararının verilmesinde salt gözlem oranından başka istatistiksel yöntemler de kullanılabilmektedir.

k-en yakın komşuluk. Sınıflandırma yöntemleri arasında anlaşılması ve uygulaması en basit olan yöntemlerden olan KYK ile bir gözlemin sınıf tahmini, sınıflandırma uzayında en yakınında bulunan $k$ sayıda gözlemin sınıf bilgisine bağlı olarak yapılır. Örneğin, $k$ değerinin 5 olduğu bir KYK'de, yeni bir gözlemin en yakınında bulunan 2 gözlem negatif, 3 gözlem pozitif sınıfa ait ise tahmin, pozitif sınıftan yana olacaktır $(3 / 5>2 / 5)$. KYK, basitliğine rağmen oldukça başarılı sonuçlar verebilmektedir. $k$ parametresinde yapılacak değişiklikle oluşturulan sınıflandırıcı eğrisi, gözlem sınıflarını yakından takip ederek karmaşık yapıların tespit edilmesini sağlayabilmektedir. Düşük parametre değerlerinde sınıflandırıcı gözlemlere karşı yüksek hassasiyete sahip olurken değer yükseldikçe sınıflandırıcı doğrusal bir forma dönüşür. Referans gözlem yakınlıklarının belirlenmesinde öklit ve standartlaştırılmı̧̧ öklit mesafeleri en çok çok tercih edilen ölçütlerdir².

Bayes ağları. BA, bir diğer adıyla yönlü çizgeler, Bayes yorumlaması kullanılarak çeşitli çıktıların ortaya çıkma olasılıklarının hesaplandığı yöntemlerdir. A $\breve{g}$ boyunca birbirlerine koşullu ilişkilerle bağlanan değişkenlerin, Bayes kurallarına bağlı olarak marjinal olasılıklarından ortak bir olasılık dağılımı elde edilir ve nihai olarak, tahmin edilmeye çalışılan sonucun ortaya çıkış olasılığı hesaplanır. Bu şekilde gözlemlerin belirli bir sınıfa aidiyetlerinin sonul olasılıkları hesaplanır. Ağ yapısı oluşturulurken, tahmin değişkenleri arasındaki nedensellik

2 Diğer metrik bilgileri için Chomboon, Chujai, Teerarassammee, vd. (2015)'in çalışmasına başvurulabilir. 
ilişkilerinin doğru şekilde belirlenmesi gerekir. BA, özellikle sebep-sonuç ilişkilerinin ortaya konması ve değerlendirilmesi bağlamında oldukça yararlı bir yöntemdir.

\section{Bulanık mantık}

BM gözlemleri sınıflandırırken kesin ayrımlar yerine sayısal olarak ifade edilen doğruluk derecelerini kullanır. BM'de bir gözlem belirli bir oranda (olasılıkta) pozitif sınıfa ait iken belirli bir oranda da negatif sınıfa ait olabilecektir. Bulanık sisteme sunulan girdiler, bulanıklaştırma adı verilen süreç içerisinde belirli üyelik fonksiyonları (girdinin herhangi bir bulanık kümeye aidiyetini gösteren matematiksel ifadeler) ile çeşitli dilsel ifade ve terimlere bağlı olarak bulanık kümelere atanır. Örneğin kredi başvurusunda bulunan bir müşteri yaşına bağlı olarak "çok genç, genç, orta yaşlı, yaşl1, çok yaşlı" gibi sınıflarla ifade edilen kümelere ait olabilir. Kümeler arası sınırlar kesin değerler ile belirlenmez. Ortaya çıkartılan bulanık bilgi çeşitli kurallara ("eğer-değilse", "VE", "VEYA" gibi operatörler ile) bağlı olarak yorumlanır ve gözlemler son aşamada, durulaştırma ile kesin sınıflara (kredi başvurularının "iyi”" ve "kötü" kategorileri gibi) atanır. BM bileşenleri başka yöntemler ile bir arada kullanılarak (örneğin ANFIS) yöntem performansının artırılmasına katkı sağlayabilmektedir.

\section{Metasezgisel algoritmalar}

Bir metasezgisel algoritma, en iyi çözümü garanti etmemekle birlikte uygulanabilir ve yüksek başarıya sahip çözümler üretebilen optimizasyon tekniğidir. En iyi çözümü veren "kesin” optimizasyon yöntemleri, olası tüm çözüm kombinasyonlarının ve aday çözüm oluşturma sürelerinin problem büyüklüğüne bağlı olarak hızla arttığı durumlarda yetersiz kalabilmektedir. "Hesaplama karmaşıklığı" ile ifade edilen ve bir algoritmanın çalıştırılması için gereken -büyük ölçüde zaman olarak ifade edilen- kaynak ihtiyacının çok büyük değerlere ulaştığ 1 durumlarda anlamlı bir süre içerisinde çözüm elde edebilmek için seçenek olarak algoritmanın iyileştirilmesi, problemin basitleştirilmesi ya da çözülebilir alt problemlere ayrıştırılması gerekecektir. Algoritmanın iyileştirilmesinin mümkün olmadığı durumlarda, kalan iki seçenek, elde edilecek çözümün/çözümlerin gerçek dünya uygulamalarını etkisizleştirebilecektir. Metasezgisel algoritmalar, yüksek karmaşıklığa sahip optimizasyon problemlerinde en iyi çözümü garanti etmeyen ancak iyileştirme sağlayan "sezgisel” yaklaşımlar kategorisinde yer alırlar. Problemlere özgü olarak tasarlanan sezgisel algoritmalardan farkları, problemlerden bağımsız çalışma mekanizmalarına sahip ve kolaylıkla uyarlanabilir olmalarıdır.

Genetik algoritma (GA). Darwin' in evrim teorisinden esinlenerek tasarlanmış olan GA'da çözüm uzayı ${ }^{3}$ taraması, çok sayıda aday çözümden oluşan popülasyonların, nesiller olarak ifade edilen çevrimler boyunca genetik operatörler aracılığıyla değişime uğraması ile gerçekleştirilir. Her nesil başlangıcında, belirli seçim kurallarına bağlı olarak ebeveyn çözümler 
belirlenir. Bu çözümler, çaprazlama adıverilen operatör ile karşılıklı bilgi aktarımına tabi olurlar ve böylece popülasyon büyüklüğünü sağlayacak sayıda yeni çözümler (çocuklar) oluşturulur. Çözüm uzayında daha geniş alanların taranmasını sağlayan mutasyon operatörü ile de yeni çözümler, belirli bir olasılığa bağlı olarak değişime uğratılır. Eski nesil içerisinden seçilen en iyi uygunluğa sahip çözümler yeni nesil içerisinde en kötü uygunluğa sahip çözümlerin yerini alır (seçkincilik-elitizm) ve böylece bir sonraki nesli oluşturacak popülasyon belirlenmiş olur. Söz konusu işlemler, belirli sayıda nesil boyunca devam ettirilir.

Genetik programlama (GP). GP'nin çözüm uzayı tarama süreci, GA ile benzer şekilde gerçekleştirilir. GP'yi GA'dan ve diğer metasezgisel algoritmalardan ayıran en önemli özellik, çözüm kodlamasının bir vektör yerine ağaç yapısına benzer şekilde yapılmasıdır. Ağaçların boyut, yapı ve karmaşıklığı çözüm uzayının taranması sırasında dinamik olarak değiştirilebilir. GP çözümlerinde programlama dil ifadeleri (VE, VEYA, EĞER-İSE, +, -, vb.) rahatlıkla yer alabilmektedir. Bu özelliği ile GP değişken/parametre seçimi ve sınıflandırma becerisine aynı anda sahip olur; yalnızca çözüm gösterimi veren bir yöntem olmanın ötesinde tek başına sınıflandırıcı olarak da kullanılabilmektedir.

Parçacık sürü optimizasyonu (PSO). Karıncalar, kuşlar, arılar ve balıklar gibi türlerde yiyecek bulma, göç etme, tehlikelere karşı önlem alma gibi temel canlı davranışları çoğunlukla bireylere bağlı olarak değil, bireylerin bilgi ve becerilerinin ortaklaşa kullanıldığ 1 ve geliştirildiği sürü davranışları içerisinde gerçekleştirilir. "Sürü zekâsı" olarak ifade edilen bu davranış biçimleri PSO gibi çeşitli iyileştirme yöntemlerine ilham kaynağı olmuştur. Bir "sürü”, içerisinde çok sayıda, basit davranış özellikleri sergileyen ve homojen ajan (aday çözüm) popülasyonu bulundurur. Ajanların merkezi bir kontrolden bağımsız olarak birbirleriyle iletişime geçmeleri ile problemlerin çözümüne yönelik karmaşık davranış örüntüleri ortaya çıar. PSO içerisinde de ajanların, çözüm uzayındaki konumlarını belirten bir konum bilgisi ve sonraki konumlarını belirleyecek bir hız bilgileri bulunur. Kendi geçmiş ve en iyi konum (en iyi çözüm) bilgilerinin yanı sıra sürüye ait geçmiş bilgileri de kullanarak her ajan, çözüm uzayında belirli noktalara doğru hareket ederek genel en iyi çözüme ulaşmaya çalışır. PSO’ların kodlanma ve çalıştırılması, diğer algoritmalara göre çok daha basit ve maliyetsizdir. Yalnızca birkaç matematik operatörü ile etkin bir optimizasyon modeli kurmak mümkün olabilmektedir.

Tavlama benzetimi (TB). Kredi risk değerlendirme çalışmalarında kendisine fazla yer bulmasa da oldukça popüler bir metasezgisel olan TB, çözüm uzayında yerel en iyiye takılmadan arama yapma becerisi ile oldukça etkin bir optimizasyon yöntemidir. Yöntem adını ve çalışma prensibini, metallerin erime noktalarının üzerindeki sıcaklıklara kadar 1sıtılması ve sonrasında kontrollü bir şekilde soğutularak (tavlama) ilk hallerinden daha düzenli kristal yapıya sahip olmalarını sağlayan süreçten almaktadır. Başlangıçta tek bir çözüm bulunur. Her seviyede (sıcaklık derecesinde) çözüm, rasgele değişikliklere uğratılarak komşuluk taraması yapılır ve daha iyi bir çözümün bulunması ya da Metropolis kriteri adı verilen koşulun sağlanması du- 
rumunda yeni çözüme hareket edilir. Metropolis kriteri, GA ve GP'de popülasyon oluşturulması sırasında kötü çözümlerin de kullanılmasına benzer şekilde, yerel en iyi çözümlerden başka iyi çözümlere ulaşılmasını sağlayan önemli bir algoritma bileşenidir. Kritere göre oluşturulan komşuluktaki bir çözüm daha kötü bir performansa sahip de olsa, algoritmanın mevcut sıcaklık seviyesi kullanılarak hesaplanan bir olasılığa bağlı olarak kabul edilebilir. Her seviyede belirli defa komşuluk hareketi yapıldıktan sonra sistem yeni ve daha düşük bir seviyeye güncellenir. Benzetim, bir sonlandırma seviyesine ulaşılınca sona erdirilir.

Tabu arama (TA). TA algoritması, TB'ye benzer şekilde tek bir çözümün değiştirilmesi ile ilerler. TA'da da aday çözümlerden oluşturulan bir komşuluk oluşturulur ancak burada komşuluğa hareket, daha iyi bir çözümün elde edilmesi ya da Metropolis kriteri gibi bir kabul koşullarına bağlı olarak yapılmaz. Tabu (yasak) listesi adı verilen kısa vadeli bir bileşene bağlı olarak mevcut çözümün, tekrarlı yapılar içerisine düşmesini engelleyecek komşuluk hareketleri engellenmeye çalışılır ve her hareket sonrası listede güncelleme yapılır. Tabu listesi, belirli bütün bir çözüme hareketi kısıtlayabileceği gibi çözümdeki bazı özelliklere bağl1 kısıtlamalar da içerebilir.

\section{Yöntem}

Kredi risk değerlendirmesinde sınıflandırma yöntemleri ve meta-sezgisel algoritmalar kullanımına ilişkin çalışmaların ortaya çıkartılabilmesi için üç anahtar kelime grubu kullanılmıştır. İlk grup: "credit scoring", "credit evaluation", "credit assessment", "credit risk assessment", "credit decision"; ikinci grup: "classification", "data mining", "machine learning", "statistical learning", "soft computing", "computational intelligence"; üçüncü grup: "metaheuristic", "evolutionary computing", "heuristic", "genetic algorithm", "genetic programming", "swarm intelligence", "evolutionary programming" kelimelerinden oluşmaktadır. 


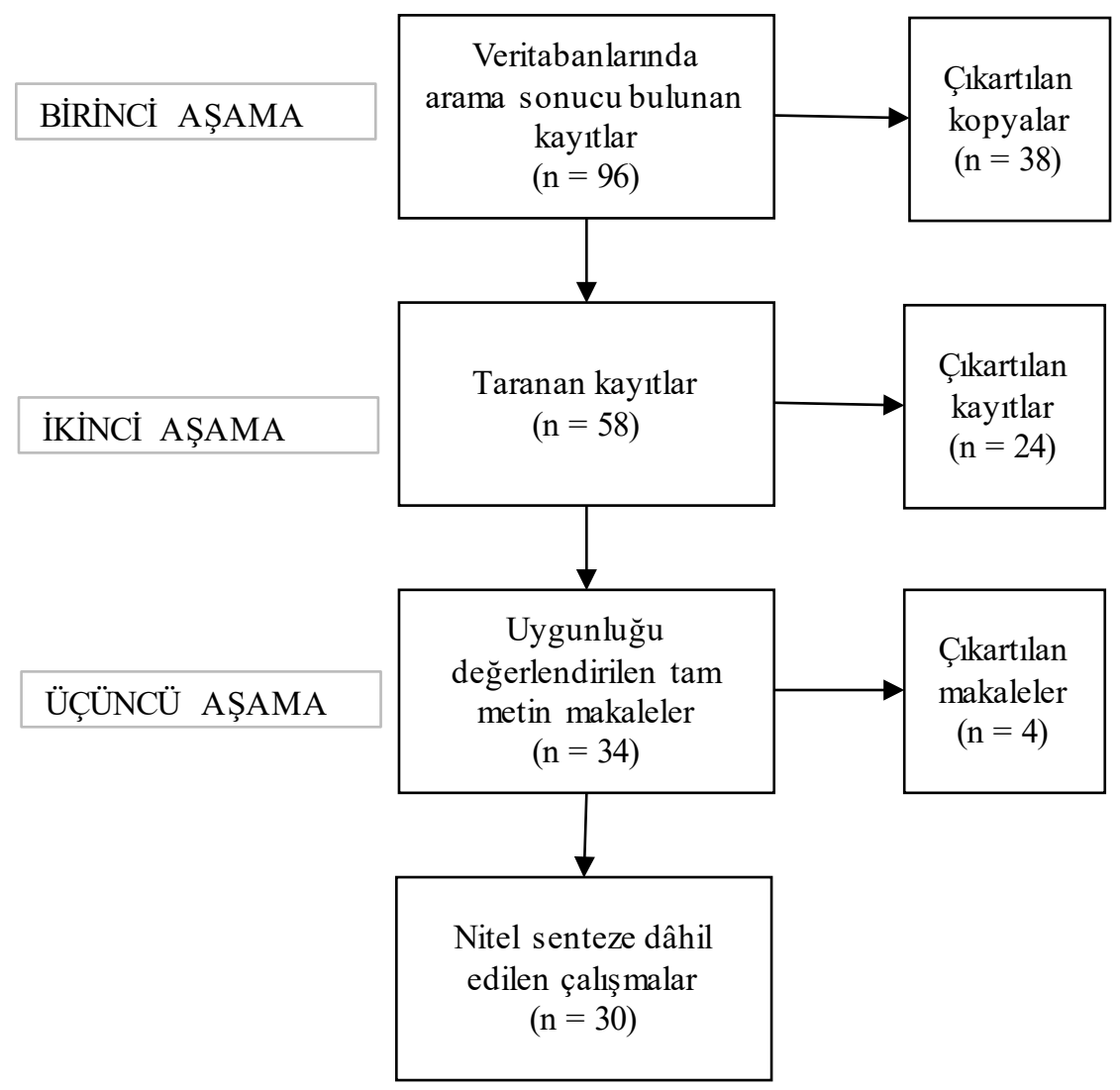

Şekil 1. Çalışmada yürütülen sistematik derleme süreci

Birinci, ikinci ve üçüncü gruptaki kelimeler birlikte kullanılarak Web of Science, Scopus ve ProQuest veri tabanlarında arama gerçekleştirilmiştir. Tarama dönemi olarak 2000-2018 yılları arası seçilmiştir. 2000 yılından başlayarak, özellikle bilgi işleme kapasitelerinde yaşanan artışlar ile şekillenen çalışmaların ortaya konması hedeflenmiştir. Anahtar kelime grupları, çalışmaların başlık, özet ve anahtar/endeks kelime kısımlarında aranmış, yalnızca İngilizce dilinde makaleler seçilmiştir ${ }^{4}$. Taramalar sonucu bulunan çalışmalar, PRISMA (Moher, Liberati, Tetzlaff, Altman ve Prisma Group, 2009) önerisine göre Şekil 1'de gösterilen sistematik derleme sürecinden geçirilmiştir.

İlk aşamada, çalışmaların farklı veri tabanlarında bulunan kopyaları tespit edilmiş ve listeden çıkartılmıştır. İkinci aşamada, çalışmaların başlık ve özet bilgileri taranmış ve sistematik tarama sürecinin bir sonraki aşamasına dâhil edilecek çalışmalar Tablo 2'de sunulan kriterlere 
göre belirlenmiştir. Üçüncü aşamada çalışmaların tam metinleri taranmış, özetleri ile anlaşılamayan ve ikinci aşamada kullanılan kriterleri sağlayamayanlar kapsam dışında tutulmuştur.

\section{Bulgular}

Bu bölümde sistematik derleme süreci sonucu elde edilen bulgular sunulmaktadır. Bir önceki bölümde bahsedilen derleme sürecindeki aşamaların ardından değerlendirmeye alınan çalışmalar, kronolojik sıra ile Ek’te verilmiştir.

Tablo 2

Taranan Çalışmaların Seçim ve Elenme Kriterleri

\begin{tabular}{lcc}
\hline Kriter & Dâhil edilen & Dâhil edilmeyen \\
\hline Çalışma türü & Dergi makalesi & $\begin{array}{c}\text { Derleme makaleleri, tam-metin konferans } \\
\text { yayınları, patentler, tezler }\end{array}$ \\
Çalışma konusu & $\begin{array}{c}\text { Finansal kredi verme kararı, şirket güvenilirlik } \\
\text { sinıflandırma, iflas tahmini }\end{array}$ & E-ticaret, P2P borçlanma \\
Çalışma amacı & Sinıflandırma, sınıflandırma performansını & artırma \\
Yöntem & Meta-sezgisellerin tek başı, birleşik, hibrit \\
kullanım önerileri & Salt yöntem karşılaştırmaları, sınıflandırma \\
Veri kümesi & Hepsi & yöntemi harici öneriler
\end{tabular}

Şekil 2'de gösterilen yıllara göre yayınlanan çalışma sayısı grafiğinde, 2005 yılı sonrası yazında her yıl en az bir kez kredi değerlendirmesinde metasezgisel yöntem kullanılan çalışma örneği olduğu ve 2015 yılından itibaren çalışma sayılarında düzenli bir artış eğilimi olduğu görülmektedir. Bu artışın arka planında, metasezgisel yöntemlerin finans çalışmaları yürütenler tarafından daha fazla bilinir olmasının ve bilgisayar bilimciler ile mühendislerin de katılımı ile disiplinlerarası etkileşimin çoğalmasının etkisi olduğunu söylemek mümkündür. Temel çalışma konusu veri analizi olan alanlarda yaşanan gelişmeler, kredi risk değerlendirmesinde finansal sektöre büyük fayda sağlama potansiyeli taşımaktadır. 


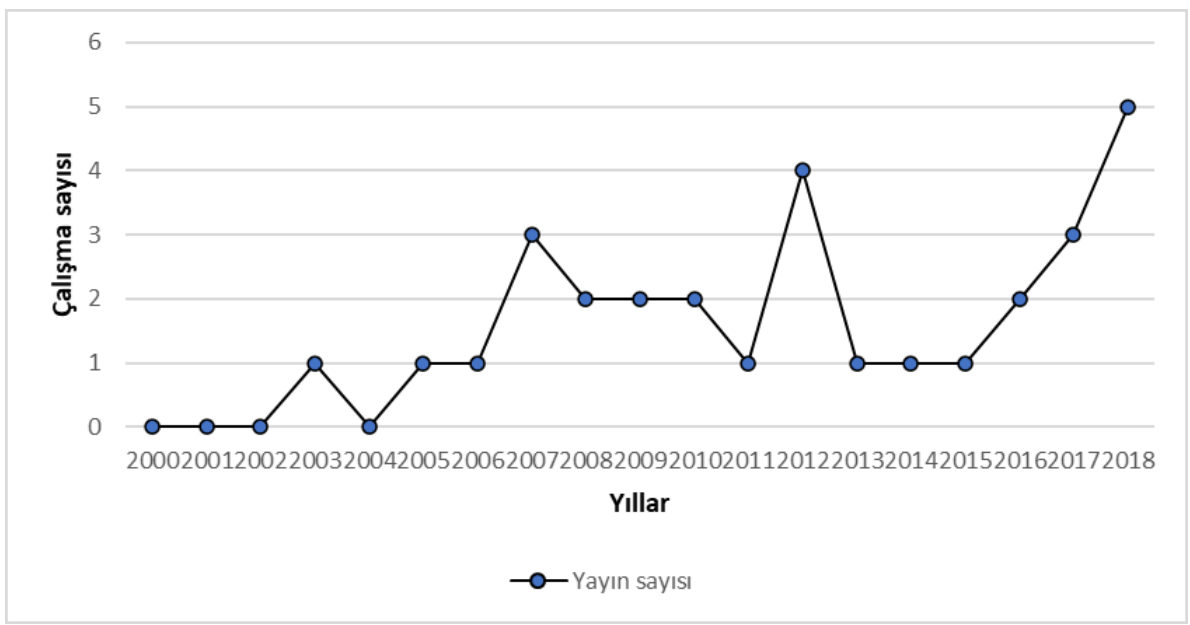

Şekil 2. Yıl bazında yayınlanan çalışma sayıları

Bu derleme kapsamında nitel senteze dâhil olan çalışmalarda temel sınıflandırıcı olarak kullanılan yöntemlerin kullanım oranları Şekil 3'te gösterilmiştir. Tercihlerin, başta SA ve DVM olmak üzere çok büyük ölçüde makine öğrenme yöntemlerinden yana kullanıldığı görülmektedir. Tercih siralamasında SA ve DVM'den sonra gelen tüm yöntemlerin kullanım oranları birbirine yakındır.

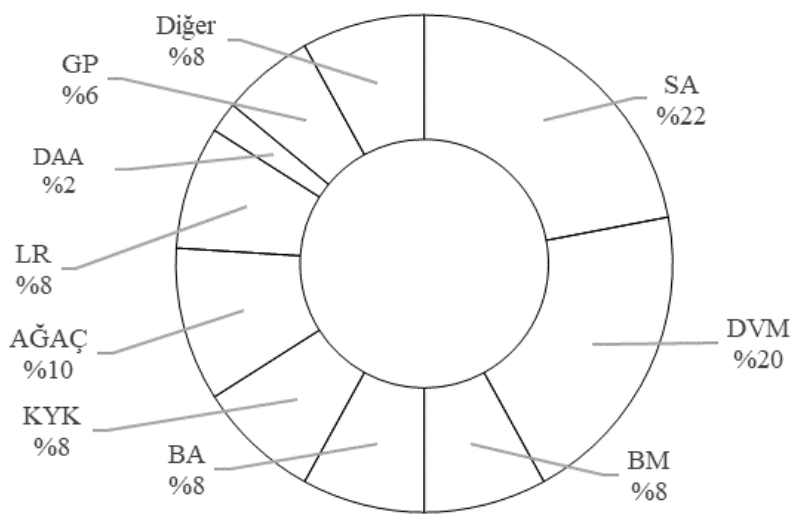

Şekil 3. Çalışmalarda kullanılan temel sınıflandırıcılar

Kredi değerlendirme çalışmalarında metasezgisel algoritmaların, öğrenme yöntemlerinin sınıflandırma performanslarını artırmaya yönelik olarak kullanım örneklerinin artış içerisinde olduğu görülmektedir. İncelenen çalışmalarda kullanılan metasezgisel algoritmalar ve kullanım oranları Şekil 4'te gösterilmiştir. Çalışmaların yarısından fazlasında GA tercih edildiği görülmektedir. Tüm metasezgisel algoritmalarda, ele alınan probleme uygun bir çözüm gösterimi (kodlaması) kullanılmaktadır. En tipik örneğiyle değişken seçiminde bir çözüm, veri kümesindeki bağımsız değişkenlerin her birine karşılık hücrelerinde 1 (dâhil edilen) ya da 0 (dâhil 
edilmeyen) değeri alabilen bir vektördür. Her bir çözüm için amaç değerine bağlı olarak bir uygunluk değeri hesaplanır ve çözüm, problemin amacına (maksimizasyon ya da minimizasyon) uygun olarak değerlendirmeye alınır.

Şekil 5'te metasezgisel algoritmaların çalışmalarda karşılaşılan kullanım amaçları verilmiştir. Kredi değerlendirme çalışmalarında metasezgisel algoritmalar çok büyük oranda değişken seçimi için kullanılmaktadır $(\approx \% 63)$. İkinci kullanım amacı ise model parametre tasarımlarının optimizasyonudur $(\approx \% 33)$.

Değişken seçimi. Kredi değerlendirme çalışmalarında sıkça karşılaşılan ve gözlemlere ait çok sayıda değişken içeren veri kümelerinin analiz ve sınıflandırma performanslarının artırılmasına yönelik olarak en fazla uygulanan iyileştirme yöntemlerinden bir tanesi değişken seçimidir. Az sayıda gözleme karşılık çok sayıda tahmin değişkeni içeren tıp ve biyoloji gibi alanlarda başta olmak üzere problem boyutunun küçültülmesi ile deterministik (rasgele faktörlerin yoğun olduğu problemlerde yöntemlerin, her çalıştırmada aynı sonuca ulaşması durumu) bir çözüme ulaşmak mümkün olabilmekte, analiz süreleri ciddi anlamda düşürülebilmekte ve çözümlerin kalitesi artırılabilmektedir. Değişken seçimi, kredi değerlendirme çalışmalarında çok boyutluluk sorunundan ziyade ilgisiz, fazla ve birbirleriyle yüksek korelasyona sahip değişkenlerin elenmesi amacıyla yapılmaktadır. Modellenen problemlerin gerçek doğası hakkında kesin bilgiye sahip olunamadığından değişken seçimi yöntemleri ile bağımlı-bağımsız değişkenlerin arasındaki ilişkileri daha doğru analiz edebilmek ve böylece yüksek sınıflandırma başarısına ulaşmak mümkün olabilmektedir.

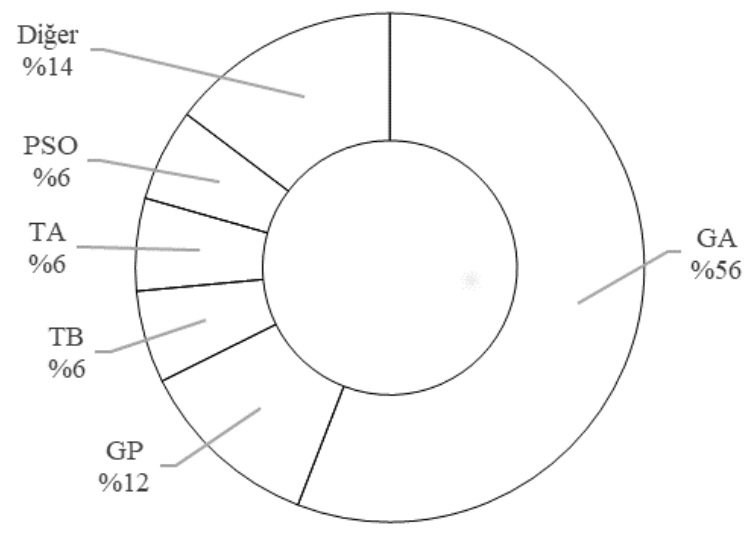

Şekil 4. Çalışmalarda kullanılan metasezgisel algoritmalar

Değişken seçimi, sınıflandırma çalışmalarında başı başına bir problem olarak önemli bir yere sahiptir. Hangi değişken kombinasyonunun en iyi sınıflandırma performansını sağlayacağı önsel olarak bilinemediğinden optimum çözümün belirlenmesi için tüm alternatiflerin denenmesi gerekmektedir. Alternatif sayısı da aday değişken sayısına bağlı olarak üstel artış göstermektedir. Bu tür optimizasyon problemleri NP-zor sınıfına girmektedir ve metasezgisel 
algoritmalar, algoritmaların tanıtıldığg bölümde de belirtilen sebeplerle değişken seçimine yönelik olarak sıkça kullanılmaktadır.

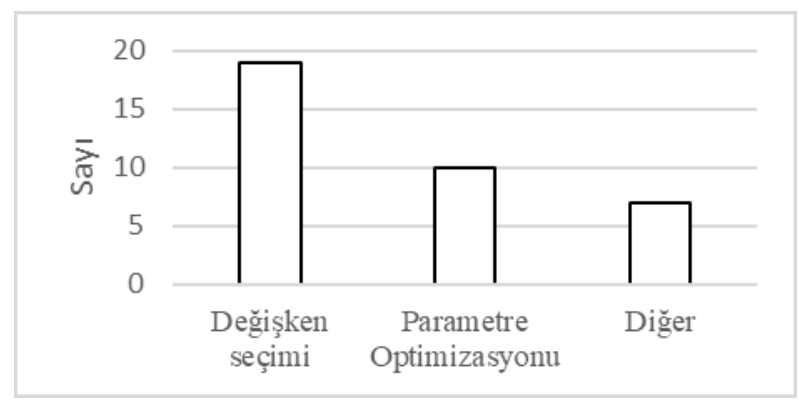

Şekil 5. Metasezgisel algoritmaların kullanım amaçları

Çalışmalarda karşılaşılan, metasezgisel algoritmalar hariç değişken seçim yöntemleri arasında ileri-geri yönde seçim, bilgi kazancı, kazanım oranı ve gini endeksi bulunmaktadır. İleriye ve geriye doğru seçim, değişkenlerin modele adım adım dahil edilmesi (çıkartılması) ile gerçekleştirilir. Boş (tüm değişkenler) ile başlanan süreç boyunca her aşamada, sınıflandırma performansına en fazla katkı sağlayan değişken eklenir (çıkartılır) ve süreç, herhangi bir iyileşmenin gerçekleşmediği aşamada sonlandırılır. Bilgi kazancı, kazanım oranı ve gini endeksi yöntemleri ile değişkenler, aldıkları değerlere bağlı olarak veri uzayında bölümleme yapıldığında ortaya çıkan bilgiye (doğru sınıflandırma başarısına) göre sıralanırlar. En çok bilgi sağlayan değişkenler sınıflandırma için kullanılır5 ${ }^{5}$.

Parametre optimizasyonu. İstatistiksel ve makine öğrenme yöntemlerinin birçoğu, sınıflandırma performansları üzerinde direkt etkiye sahip ayarlama parametrelerine sahiptir. Değişken optimizasyonuna benzer şekilde parametrelerin belirlenmesi süreci de yüksek karmaşıklığa sahip bir problem türüdür. Ayarlanabilir parametre sayısı az da olsa, alabilecekleri değerler çok fazla olabilmektedir. Özellikle sürekli değer alabilen parametrelerde sonsuz alternatif bulunabilir. Metasezgisel algoritmalar, değişken seçimine benzer sebeplerden dolayı parametrelerin optimizasyonu için de kullanışlı yöntemler olarak tercih edilebilmektedir. Bir metasezgisel algoritma ile aynı anda hem değişken seçimi hem de parametre optimizasyonu yapılan çalışmalar mevcuttur (Gorzałczany ve Rudziński, 2016; Huang ve diğerleri, 2007; Liu ve diğerleri, 2010; Oreski ve diğerleri, 2012).

\section{Veri kümeleri}

Önerilen yöntemlerin diğer yöntemler ile karşılaştırılmasında kurumlardan toplanan veriler kullanılabildiği gibi, kıyaslama amaçlı olarak internet veri tabanlarında bulunan veri kümeleri de kullanılabilmektedir. Kıyaslama amaçlı kullanılan veri kümeleri ile yöntemler, aynı veri kümelerinin kullanıldığı yazındaki diğer çalışmalardaki yöntemler ile karşılaştırılabilmektedir. Taranan çalışmalarda analiz edilen veri kümeleri Şekil 6’ da gösterilmiştir. 


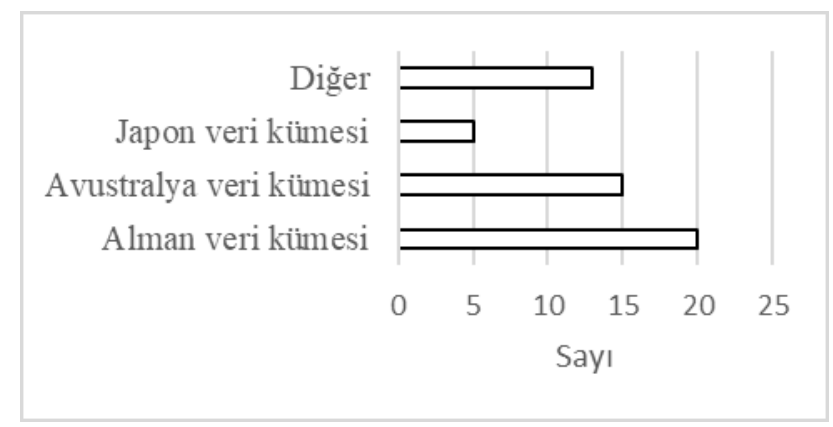

Şekil 6. Çalışmalarda analiz edilen veri kümeleri

Alman veri kümesi. En çok tercih edilen kiyaslama kümesi, UCI (Dua ve Graff, 2017) veri tabanında bulunan Alman veri kümesidir. Veri kümesinde 1000 adet gözlem bulunmaktadır (\%70 iyi, \%30 kötü sınıfa ait). Her gözlemin 7 adet sayısal ve 13 adet kategorik tahmin değişkeni bulunmaktadır. Veri kümesinin ayrıca, 24 sayısal değişkenden oluşan ayrı bir biçimi de bulunmaktadır. Alman veri kümesi ile sınıf dengesizliği (7:3 oranı) etkileri de çalışılabilmektedir.

Avustralya veri kümesi. Alman veri kümesinden sonra en çok tercih edilen kıyaslama kümesi olan Avustralya veri kümesinde (Dua ve Graff, 2017) yaklaşık olarak \%44 iyi, \%55 kötü sınıfa ait gözlem bulunmaktadır. Her gözlem için 6 sayısal 8 kategorik tahmin değişkeni vardır. Avustralya veri kümesi, Alman veri kümesine göre daha dengeli bir sınıf dağılımına sahiptir.

Japon veri kümesi. Japon veri kümesi (Dua ve Graff, 2017), Avustralya veri kümesine benzer şekilde $\% 44$ oranında iyi, \%55 oranında kötü sınıfa ait toplam 690 gözlem içermektedir. Her gözlem için 6 sayısal 9 kategorik tahmin değişkeni bulunmaktadır.

\section{Performans kriterleri ve doğrulama metotları}

Kredi risk sınıflandırma çalışmalarında yöntem performanslarının değerlendirilmesine yönelik belli başlı göstergeler kullanılmaktadır. Bu yaklaşımların hepsinde, doğru ve yanlış olarak sınıflandırılan gözlemlerin sayısının gösterildiği karışıklık matrisi değerleri kullanılmaktadır. Tablo 3 'te iki sınıflı bir kredi değerlendirme probleminde kullanılan karışıklık matrisi örneği 6 gösterilmiştir.

6 Tablo, kredi sınıflandırma çalışmalarının çok büyük bir bölümünü oluşturan iki sınıflı bir problem örneğine uygun olarak düzenlenmiştir. 


\begin{tabular}{cccc}
\hline & & \multicolumn{2}{c}{ TAHMIN EDİLEN SINIFLAR } \\
\hline & & IYYİ & KÖTÜ \\
\hline GERÇEK & IYYİ & DOĞRU NEGATİF (DN) & YANLIŞ POZITIF (YP) \\
SINIFLAR & KÖTÜ & YANLIŞ NEGATİF (YN) & DOĞRU POZITİF (DP) \\
\hline
\end{tabular}

Tabloda negatif olarak adlandırılan değerler temerrüde düşmeyen başvuruları, pozitif olarak adlandırılanlar ise temerrüde düşen sınıfları temsil etmektedir. Tablodaki değerlere göre tahmin doğruluğu, özgüllük ve hassasiyet gibi istatistikler elde edilir.

Tahmin doğruluğu. Tahmin doğruluğu, sınıflandırıcının tüm gözlemler içerisinde yaptığ1 doğru sınıflandırmaların oranıdır:

$$
\text { Tahmin doğruluğ } u=\frac{D N+D P}{D N+D P+Y N+Y P}
$$

Tahmin doğruluğu, kredi risk sınıflandırma çalışmalarında en çok tercih edilen performans kriteridir. Çeşitli çalışmalarda tahmin doğruluğu yerine hata oranı (1- tahmin doğruluğu) değerinin de kullanıldı̆̆ 1 görülmektedir.

Özgüllük. Sınıflandırıcının negatif gözlemleri ne ölçüde doğru sınıflandırdığının göstergesidir:

$$
\ddot{O} z g \ddot{u} l l \ddot{u} k=\frac{D N}{D N+Y P}
$$

Özgüllük değeri aynı zamanda TİP-I kesinlik ölçüsüdür. Özgüllük ile TİP-I hata olarak adlandırılan YP oranı (1- özgüllük) hesaplanabilir.

Hassasiyet. Sınıflandırıcının pozitif değerleri doğru şekilde tespit etme gücü hassasiyet ile ölçülür:

$$
\text { Hassasiyet }=\frac{D P}{Y N+D P}
$$

Hassasiyet aynı zamanda TİP-II kesinlik olarak da bilinir.

İncelenen çalışmaların çok büyük bir kısmında ( $\approx \% 73)$ sınıflandırıcı performans göstergesi olarak tahmin doğruluğu kullanılmaktadır. Bazı çalışmalarda ise tahmin doğruluğunun yanı sıra, karışıklık matrisinden yukarıda bahsedilen şekilde hesaplanan özgüllük (TİP-I kesinlik) ve hassasiyet (TIPP-II kesinlik) de raporlanmaktadır ${ }^{7}$ (\%30). Özgüllük ve hassasiyet, sınıflandırıcı performanslarının probleme ve veri kümesine bağlı unsurlarının ortaya çıkartılması

7 Yazının geneline zıt olarak hassasiyet ve özgüllük bazı çalışmalarda (örneğin, Altinbas ve Akkaya (2017), Chi ve Hsu (2012), Oreski ve diğerleri (2012), Oreški ve Oreški (2018)'de), sırasıyla TİP-I ve TİP-II kesinlikler ile ilişkilendirilmektedir. Bu çalışmada genel kabul gören eşleştirme benimsenmiştir. 
açısından önemlidir. Geri ödemelerinde aksamalar olan ya da hiçbir zaman ödenmeyen sorunlu krediler bankaların bilançolarında vade uyumunu bozmakta, aktif kalitesi, kârlılık, sermaye yeterliği gibi oranlarda olumsuz etkiler yaratmaktadır. Bu sebeple "kötü" olarak kategorize edilebilecek bir başvurunun yanlış değerlendirme sonucu onaylanması ile yaşanan kayıp, "iyi" bir başvurunun reddedilmesinden dolayı kaybedilen getiriden çok daha fazla olacaktır.

Çalışmaların hemen hepsinde temel amaç genel tahmin performansının en büyüklenmesi olsa da hassasiyetin de ek bir gösterge olarak (örneğin tahmin doğruluğu ve hassasiyetin hedef fonksiyon olarak bir arada değerlendirilmesi ile) çalışmalarda daha fazla yer alması ve incelenmesi gerekmektedir. Özgüllük ve hassasiyet etkisini ölçmenin alternatif bir yolu olarak Abdou (2009)'un çalışmasında görüldüğü gibi, YN ve YP miktarlarının farklı maliyet katsayılarıla çarpılması ve toplanması ile hesaplanan yanlış sınıflandırma maliyeti de kullanılabilir.

İncelenen çalışmaların bir kısmında ( $\approx 23)$, sınıflandırıcıların pozitif sınıfları tanılama performanslarının görülebilmesini ve yöntemlerin karşılaştırılmasını sağlayan alıcı işletim karakteristiği (receiver operating characteristic - ROC) eğrisinin kullanıldığı görülmektedir. ROC eğrisi, sınıflandırma yöntemi tarafından sınıfı tahmin edilmeye çalışılan gözlem için üretilen sonsal olasllık (posterior probability) değerinin, gözlemin pozitif sınıfa ait olması için gereken sınıflandırma eşik değerlerine (minimum olasılıklara) bağlı olarak başarılı şekilde tespit ettiği pozitif sınıf oranı (hassasiyet) ile yanlış tahmin ettiği pozitif sınıf oranı (1- özgüllük) arasındaki ilişkiyi gösterir. Örnek bir ROC eğrisi, Şekil 7'de görülebilir.

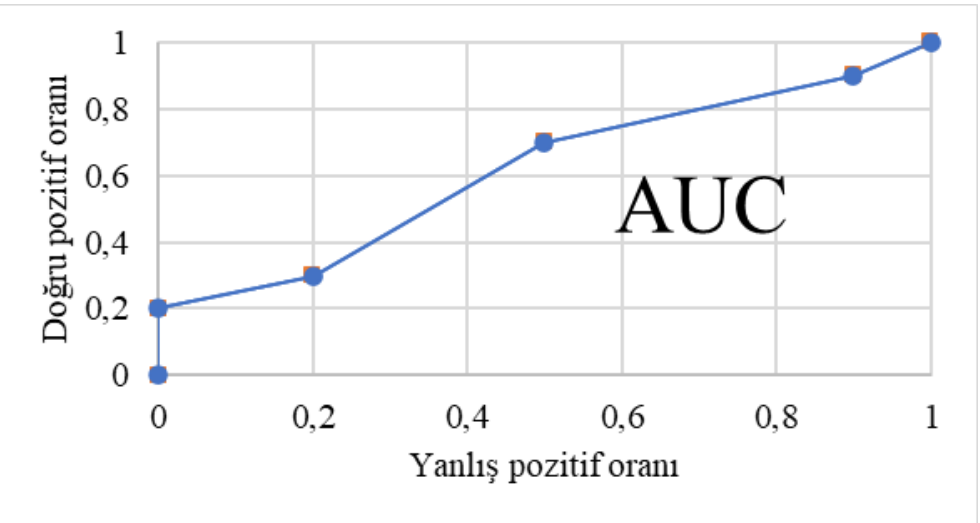

Şekil 7. ROC eğrisi ve AUC 
Eğrinin altında kalan alan (area under curve- AUC), iki farklı göstergenin- DP ve YP oranlarının- tek bir istatistik ile gösterimini sağlamaktadır. 0-1 aralığında değer alan AUC ne kadar büyükse, modelin pozitif sınıfları tespiti o derece güvenilir olacaktır. Farkı sınıflandırma yöntemleri, ROC eğrileri ve AUC istatistikleri göz önüne alınarak kolaylıkla karşılaştırılabilmektedir. Bu göstergeler dışında, pozitif ve negatif grupların kümülatif dağılım fonksiyonları arasındaki farkı gösteren Kolmorogov-Smirnoff (K-S) istatistiği ve F-skorunun da kullanıldı̆̆1 görülmektedir:

$$
F-\text { skoru }=\frac{2}{\frac{1}{\text { Hassasiyet }}+\frac{Y P+D P}{D P}}
$$

Her iki performans değeri de 0 ile 1 arasında değer almakta ve 1'e yakın değerler, yöntemin sınıflandırma performansının yüksek olduğuna işaret etmektedir.

Bir sınıflandırma yönteminin gerçek tahmin performansı, yöntemin öğrenme aşamasına dâhil edilmemiş gözlemleri sınıflandırma beceresi ile ölçülmektedir. Bu sebeple veri kümeleri, yöntemin öğrenme sürecinde kullanılan "eğitim kümesi” ve performans değerlerinin elde edildiği "test kümesi” olmak üzere iki gruba ayrılmaktadır. İncelenen çalışmalarda söz konusu ayırma işlemi iki farklı strateji (çapraz doğrulama ve doğrulama/dışarıda tutma) ile gerçekleştirilmiştir.

Dışarıda tutma/ doğrulama kümesi. Bazı çalışmalarda dışarıda tutma, bazılarında ise doğrulama kümesi yaklaşımı olarak tanımlanan stratejide veri kümesindeki belirli sayıda gözlem eğitim kümesine, kalanları da test kümesine dâhil edilir. Sınıflandırma yönteminin öğrenim süreci eğitim kümesine bağlı olarak gerçekleştirilir ve yöntem performansı, test kümesindeki gözlemlerin sınıflandırılma başarısına göre değerlendirilir.

K-katlı çapraz doğrulama. Dışarıda tutma/doğrulama yaklaşımında tek bir eğitim kümesi ve tek bir test kümesi kullanılmaktadır. Bu sebeple modellerin performansları, kümeleri oluşturan gözlemlerden fazlasıyla etkilenebilmektedir. Yöntemlerin performanslarının daha doğru şekilde ölçülebilmesi için çok sayıda eğitim-test kümesi oluşturmak ve ortalama başarıyı takip etmek daha sağlıklı olmaktadır. Çapraz doğrulamada veri kümesi, $k$ sayıda ve eşit miktarda (ya da yaklaşık olarak eşit) gözlem içeren alt kümelere bölünür. İlk öğrenimde birinci bölümleme test kümesi olarak ayrılır ve geriye kalan bölümlemeler yöntem eğitiminde kullanılır. Öğrenimin performansı test kümesi üzerindeki başarı ile kaydedilir. İkinci, üçüncü ve takip eden öğrenimler de benzer şekilde bölümlemelerin test kümesi olarak ayrılması ve geriye kalanların eğitimde kullanılması ile devam eder. K bölümleme ile gerçekleştirilen küme ayrıştırmaları örneği Şekil 8'de gösterilmiştir. 


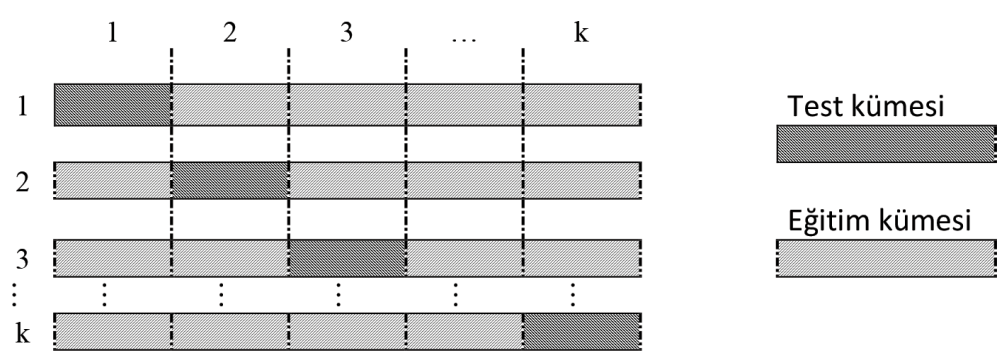

Şekil 8. K-katlı çapraz doğrulama

Tüm tekrarlar tamamlandığında yöntemin performansının ölçüsüne, önceden bahsi geçen kriterlerin ortalamaları alınarak ulaşılır. Öğrenim yanlılığı ve değişkenliğinin 8 optimizasyonu için $k$ parametresinin doğru ayarlanması önemlidir.

Çalışmaların bir kısmında ( $\approx \% 37)$ çapraz doğrulama ve doğrulama/dışarıda tutma süreçleri birden fazla defa gerçekleştirilmiştir. Böylelikle eğitim ve test kümelerine dâhil olan farklı gözlem kombinasyonlarının sebep olacağı performans farklılaşmaları incelenebilmektedir ve sınıflandırıcıların genelleştirme becerileri üzerinde daha güvenilir istatistikler elde edilebilmektedir.

\section{Tartıșma ve Sonuç}

$\mathrm{Bu}$ çalışmada kredi başvurularının sınıflandırılmasında metasezgisel algoritmaların tek başlarına ve öğrenen yöntemler ile birlikte kullanıldığ 1 çalışmaların sistematik bir derlemesi yapılmıştır. 2000-2018 dönemi için, seçili veri tabanlarında taranan bilimsel dergilerde yayınlanmış 30 adet makale nitel senteze dâhil edilmiştir. Sentez kapsamındaki çalışmalarda kullanılan sınıflandırma yöntemleri, önerilen metasezgisel algoritmalar, algoritmaların kullanım amaç ve biçimleri ile analizlerin gerçekleştirildiği veri kümeleri, analiz performanslarının ölçümünde kullanılan yöntemler ve kriterler incelenmiş ve sunulmuştur. Sentez ile incelenen dönemde, kredi değerlendirme çalışmalarında öğrenme yöntemlerinin metasezgisel algoritmalar ile birlikte kullanımında pozitif bir trendin var olduğu görülmektedir.

Çalışmaların çok büyük bir kısmında sınıflandırıcı yöntem tercihinin istatistiksel öğrenme yerine makine öğrenme yöntemleri olduğu görülmektedir. Hesaplama ve veri depolama kapasitelerinde yaşanan artışlar ve kullanım kolaylıkları yüksek yazılım araçları, daha yüksek tahmin performanslarına sahip gelişmiş makine öğrenme yöntemlerinin uygulanabilirliğini ve cazibesini artırmaktadır. Makine öğrenme yöntemleri arasında SA ve DVM, çalışmaların neredeyse yarısında kullanılmış olan yöntemler olarak ön plana çıkmıştır ve büyük ölçüde de başarılı sınıflandıııcılar olarak raporlanmışlardır.

Tüm inceleme dönemi içerisindeki payları düşük olsa da BA ve BM yöntemlerinin de son yıllarda artan bir popülaritesi olduğu görülmektedir. Bu yöntemler veri kümelerindeki göz- 
lemler ve değişkenler arasındaki belirsiz ilişkilerin kesin yapılar içerisinde ifade edildiği kapalı kutu öğrenme sistemleri yerine gerçek koşulların ayrıntılı olarak modellenebildiği alternatifler olarak kullanılabilmektedir. Gerçeğe yakın bir şekilde oluşturulan karmaşık modellerin analiz ve çözümleri için gereken bilgi işleme imkânlarının çoğalması ve yayılmasının ilgi artışını tetiklediği düşünülmektedir. Nedenselliğin ortaya konabildiği, problemlerdeki belirsizlik unsurlarının modellere daha gerçekçi şekilde yansıtılabildiği, önceden elde edilen bilginin öğrenmenin sonraki aşamalarına aktarılabildiği ve insan kavrayış ve anlayışına daha uygun sistemler tasarlamak mümkün olabilmektedir. Ancak bu yöntemler, doğru ağ yapılarının kurulumu (BA'da) ve kuralların ve üyelik fonksiyonlarının (BM'de) doğru şekilde belirlenmesi gibi öğrenme performansı üzerinde direkt etki eden unsurlar içermektedir ve büyük ölçüde uzman bilgisine ihtiyaç duyulmaktadır. Bu açılardan makine öğrenme yöntemlerinin, mevcut ham veri bolluğu içerisinde daha fazla fayda sağladığını söylemek mümkündür.

Çalışmalarda önerilen yöntem ve yaklaşımların performansları sıklıkla başka yöntemler ile karşılaştırılarak değerlendirilmektedir. Bu açıdan derleme kapsamında ele alınmış yöntemlerin çok büyük bir kısmı, önerilen esas yöntem tasarımının içerisinde yer almasalar da çalışmalarda kendilerine yer bulmaktadırlar. Veri kümelerindeki gözlem ve değişkenlere fazlasıyla bağlı olan öğrenme yöntemlerinin performansları üzerinde belirli beklentiler olabilse de kesin bir genelleme yapmak mümkün değildir ve gerçek değerlendirme ancak tüm yöntemlerin denenmesiyle yapılabilir. Yazında, farklı sınıflandırıcıların elde ettiği bilgiyi kullanarak ortak bir kararın alınmasını sağlayan kolektif/birleşik yöntem tasarımları da bulunmaktadır.

Kredi veri kümelerinin hemen hepsinde karşılaşılan çok boyutluluk, değişkenler arası yüksek korelasyon ve dengesiz sınıf dağılımları gibi problemler, bahsi geçen sınıflandırma yöntemlerinin performanslarını olumsuz olarak etkilemektedir. Bu problemlerin çözümüne yönelik olarak çeşitli optimizasyon yöntemleri önerilmektedir ve optimizasyon uygulanması ile de çoğu zaman performans artışı elde etmek mümkün olmaktadır. Söz konusu yöntemler arasında da metasezgisel algoritmaların, son 30 yıllık dönemde mühendislik, doğa ve tıp bilimleri ile sosyal bilimler alanlarında çokça tercih edildiği bilinmektedir.

Klasikleşmiş ve kesin çözüm vermek üzere tasarlanmış birçok optimizasyon yönteminin, günümüz problemlerindeki karmaşıklar karşısında yetersiz kaldığı bilinmektedir. Klasik optimizasyon yöntemlerinin çalışabilmesi için problem formüle edilirken önemli derecede basitleştirmeler yapılmakta ve çok sayıda kısıt kullanılmak zorundadır. Özellikle kredi değerlendirme çalı̧̧malarında görüldüğü üzere mevcut veri çokluğu ve ihtiyaçlar göz önüne alındığında problemlerin bu şekilde ele alınması hem anlamsız olmaktadır hem de olumsuz sonuçlar doğurabilmektedir. Metasezgisel yaklaşımlar ile eldeki tüm bilginin kullanımı mümkün olabilmektedir. Metasezgisel algoritmalar, klasik optimizasyon yöntemlerinin sağladığı "en iyi” çözüme çoğu zaman ulaşamıyor olsa da elde edilen performans iyileştirmeleri bu eksiklik karşısında çok daha anlamlı ve işe yarar görülmektedir. 
2000 sonrası dönem incelendiğinde, kredi risk değerlendirme çalışmalarında GA tercihinin baskın olduğu görülmektedir. GA, çözüm uzayı tarama ve çözüm üretme başarıları ile tercih edilir olmaktadır. Ancak yazına sürekli olarak yeni algoritmaların sunulduğu göz önüne alındığında, metasezgisel yaklaşımlar içerisinde yer alan diğer yöntemlerin de çalışmalarda daha fazla yer alması gerekmektedir. GA'dan sonra en çok tercih edilen yöntem olan GP'nin da çözüm gösterim şekli itibariyle tek başına bir sınıflandırıcı olarak kullanım avantajı sayesinde ön planda olduğunu söylemek mümkündür. GA ve GP'nin çözüm uzayı tarama mekanizmalarının benzer olduğu düşünüldüğünde, yeni geliştirilen yaklaşımların da kredi veri kümelerinin analizlerinde kullanılması yerinde olacaktır. İncelenen çalışmalar içerisinde son dönemde yalnızca bir tanesinde, farklı metasezgisel algoritmaların hibrit ya da beraber kullanımı ile daha yüksek performans elde edildiği görülmüş ve raporlanmıştır. Yeni yöntem önerilerinin yanı sıra mevcut yöntemlerin güçlü yönlerinden aynı anda yararlanılan tasarımların da alana katkı sağlayacağı aşikârdır.

Çalışmalardaki metasezgisel algoritmalar çok büyük oranda değişken seçimi için kullanılmaktadır. Bundaki temel motivasyon, bir başvurunun doğru şekilde sınıflandırılmasına katk1 sağlamayan ve performansları olumsuz etkileyen değişkenlerin analizlerden çıkartılmasıdır. Nihai analize dâhil edilen değişkenler karar vericilere, başvuruların ret ya da kabul sebeplerine ilişkin de fikir verebilmektedir. Değişkenler ile kararlar arasında sebep-sonuç ilişkisi kurularak ve başvuranlara anlamlı geri bildirimler sağlanarak hem şeffaflığın sağlanması hem de sektörün genel performansının ve başarısının artırılması hedeflerine ulaşılabilir.

Çalışmalarda analiz edilen veri kümelerine bakıldığında, çok büyük oranda referans olarak kullanılan bireysel tüketici veri kümelerinin tercih edildiği görülmektedir. Özellikle Alman veri kümesinin, önerilen yöntem(ler)in performanslarının yazın ile karşılaştırmalı olarak değerlendirilmesinde bir "altın standart" olduğu söylenebilir. Ancak söz konusu veri kümesi oldukça eski tarihlidir ve başvuru sahiplerine ait çeşitli niteliklerin (değişkenlerin) günümüzde geçerliliği bulunmamaktadır. Örneğin başvuranın bir telefonunun bulunup bulunmadığ 1 bilgisi bugün için bir anlam ifade etmemektedir. Buna rağmen dengesiz sınıf dağılımına ve kategorik/sayısal değişkenlere sahip olması gibi özellikleri, sınıflandırıcı performanslarının test edilmesi için iyi bir seçenek olmasını sağlamaya devam etmektedir. Referans veri kümeleri haricinde güncel şirket ve birey bilgilerinden oluşan veri kümeleri de kullanılmaktadır. Her bir küme tek bir çalışmaya özel olarak kullanıldığı için önerilen yöntemin yazın ile karşılaştırmasını yapmak mümkün olamamaktadır. Bu tür veri kümelerinin kullanıldığı çalışmalarda karşılaştırma ancak aynı çalışma içerisinde kullanılan klasik yöntemler ile gerçekleştirilmektedir.

Kredi risk değerlendirmesinde öğrenme yöntemleri ile metasezgisel algoritmaların kullanımı üzerine yapılan inceleme bu alanda, ileride yapılacak çalışmalara kaynak ve nirengi 
noktası olacak sağlam bir zeminin oluştuğunu göstermektedir. Kredi değerlendirmesinde kullanılan öğrenme yöntemlerinin performanslarının artırılması için yapılan değişken ve parametre seçimi süreçleri doğrusal olmayan, çok değişkenli, karmaşık yapıda özellikler gösterir ve çoğu zaman birden çok iyi çözüm alternatifine sahiptir. Bu sebeple kredi değerlendirme çalışmalarında en iyi çözümü garanti etmemekle birlikte problemlerin bahsi geçen özellik ve karmaşıklıklarına karşın kısıt kullanımına ya da basitleştirmeye gerek olmadan anlamlı iyileştirmeler sağlayan metasezgisel algoritmalara yönelik artan bir ilgi vardır. Metasezgisel optimizasyon alanına sunulan yeni yaklaşımların, paralel ve hibrit optimizasyon teknikleri gibi gelişmelerin hızlı bir şekilde kredi değerlendirme çalışmalarına dâhil edilmesi ile yazın başarılı şekilde gelişmeye devam edebilecektir.

Peer-review: Externally peer-reviewed.

Conflict of Interest: The author have no conflict of interest to declare.

Grant Support: The author declared that this study has received no financial support.

Hakem Değerlendirmesi: Dış bağımsız.

Çıkar Çatışması: Yazar çıkar çatışması bildirmemiştir.

Finansal Destek: Yazar bu çalışma için finansal destek almadığını beyan etmiştir.

\section{References}

Abdou, H. A. (2009). Genetic programming for credit scoring: The case of Egyptian public sector banks. Expert Systems With Applications, 36(9), 11402-11417. doi:10.1016/j.eswa.2009.01.076

Altinbas, H., \& Akkaya, G. (2017). Improving the performance of statistical learning methods with a combined meta-heuristic for consumer credit risk assessment. Risk Management, 19(4), 255-280.

Boughaci, D. ve Alkhawaldeh, A. A. K. (2018). A new variable selection method applied to credit coring. Algorithmic Finance, 7(1-2), 43-52. doi:10.3233/AF-180227

Chen, M. C., \& Huang, S. H. (2003). Credit scoring and rejected instances reassigning through evolutionary computation techniques. Expert Systems with Applications, 24(4): 433-441. doi:10.1016/S9574174(02)00191-4

Chen, N., Ribeiro, B., \& Chen, A. (2016). Financial credit risk assessment: a recent review. Artificial Intelligence Review, 45(1), 1-23. doi:10.1007/s10462-015-9434-х

Chi, B. W., \& Hsu, C. C. (2012). A hybrid approach to integrate genetic algorithm into dual scoring model in enhancing the performance of credit scoring model. Expert Systems with Applications, 39(3), 2650-2661. doi:10.1016/j.eswa.2011.08.120

Chomboon, K., Chujai, P., Teerarassammee, P., Kerdprasop, K., \& Kerdprasop, N. (2015). An empirical study of distance metrics for k-nearest neighbor algorithm. 3rd International Conference on Industrial Application Engineering 2015 içinde (ss. 280-285). doi:10.12792/iciae2015.051

Dua, D., \& Graff, C. (2017). \{UCI\} Machine Learning Repository. http://archive.ics.uci.edu/ml adresinden erişildi.

Gorzałczany, M. B., \& Rudziński, F. (2016). A multi-objective genetic optimization for fast, fuzzy rule-based credit classification with balanced accuracy and interpretability. Applied Soft Computing Journal, 40, 
206-220. doi:10.1016/j.asoc.2015.11.037

Habibi, A., \& Hosseini, S. S. (2016). Ranking bank customers using Neuro-Fuzzy network and optimization algorithms. International Journal of Advanced and Applied Sciences, 3(2), 40-44.

Hoffmann, F., Baesens, B., Mues, C., Van Gestel, T. ve Vanthienen, J. (2007). Inferring descriptive and approximate fuzzy rules for credit scoring using evolutionary algorithms. European Journal of Operational Research, 177(1), 540-555. doi:10.1016/j.ejor.2005.09.044

Huang, C.-L., Chen, M.-C., \& Wang, C.-J. (2007). Credit scoring with a data mining approach based on support vector machines. Expert Systems with Applications, 33(4), 847-856. doi:10.1016/j.eswa.2006.07.007

Huang, J. J., Tzeng, G. H., \& Ong, C. S. (2006). Two-stage genetic programming (2SGP) for the credit scoring model. Applied Mathematics and Computation, 174(2), 1039-1053. doi:10.1016/j.amc.2005.05.027

Huang, S.-C., \& Wu, C.-F. (2011). Customer credit quality assessments using data mining methods for banking industries. African Journal of Business Management, 5(11), 4438-4445.

Hüllermeier, E. (2005). Fuzzy methods in machine learning and data mining: Status and prospects. Fuzzy Sets and Systems, 156(3), 387-406. doi:10.1016/j.fss.2005.05.036

Jadhav, S., He, H., \& Jenkins, K. (2018). Information gain directed genetic algorithm wrapper feature selection for credit rating. Applied Soft Computing Journal, 69, 541-553. doi:10.1016/j.asoc.2018.04.033

Kaynar, O., Arslan, H., Görmez, Y. ve Işık, Y. E. (2018). Makine öğrenmesi ve öznitelik seçim yöntemleriyle saldırı tespiti. Bilişim Teknolojileri Dergisi, 11(2), 175-185. doi:10.17671/gazibtd.368583

Koutanaei, F. N., Sajedi, H., \& Khanbabaei, M. (2015). A hybrid data mining model of feature selection algorithms and ensemble learning classifiers for credit scorin. Journal of Retailing and Consumer Services, 27, 11-23. doi:10.1016/j.jretconser.2015.07.003

Lanzarini, L. C., Villa Monte, A., Bariviera, A. F., \& Jimbo Santana, P. (2017). Simplifying credit scoring rules using LVQ+ PSO. Kybernetes, 46(1), 8-16. doi:10.1108/K-06-2016-0158

Liu, X., Fu, H., \& Lin, W. (2010). A modified support vector machine model for credit scoring. International Journal of Computational Intelligence Systems, 3(6), 797-804. doi:10.1080/18756891.2010.9727742

Louzada, F., Ara, A., \& Fernandes, G. B. (2016). Classification methods applied to credit scoring: Systematic review and overall comparison. Surveys in Operations Research and Management Science, 21(2), 117-134. doi:10.1016/j.sorms.2016.10.001

Marinaki, M., Marinakis, Y., \& Zopounidis, C. (2010). Honey bees mating optimization algorithm for financial classification problems. Applied Soft Computing Journal, 10(3), 806-812. doi:10.1016/j.asoc.2009.09.010

Marinakis, Y., Marinaki, M., Doumpos, M., Matsatsinis, N., \& Zopounidis, C. (2008). Optimization of nearest neighbor classifiers via metaheuristic algorithms for credit risk assessment. Journal of Global Optimization, 42(2), 279-293. doi:10.1007/s10898-007-9242-1

Marqués, A. I., García, V., \& Sánchez, J. S. (2013). A literature review on the application of evolutionary computing to credit scoring. Journal of the Operational Research Society, 64(9), 1384-1399. doi:10.1057/ jors. 2012.145

Moher, D., Liberati, A., Tetzlaff, J., Altman, D. G., \& Prisma Group. (2009). Preferred reporting items for systematic reviews and meta-analyses: the PRISMA statement. Annals of Internal Medicine, 151(4), 264-269. doi:10.1371/journal.pmed.1000097

Ong, C. S., Huang, J. J., \& Tzeng, G. H. (2005). Building credit scoring models using genetic programming. 
Expert Systems with Applications, 29(1), 41-47. doi:10.1016/j.eswa.2005.01.003

Oreski, S., Oreski, D., \& Oreski, G. (2012). Hybrid system with genetic algorithm and artificial neural networks and its application to retail credit risk assessment. Expert Systems with Applications, 39(16), 12605-12617. doi:10.1016/j.eswa.2012.05.023

Oreski, S., \& Oreski, G. (2014). Genetic algorithm-based heuristic for feature selection in credit risk assessment. Expert Systems with Applications, 41(4), 2052-2064. doi:10.1016/j.eswa.2013.09.004

Oreški, S., \& Oreški, G. (2018). Cost-sensitive learning from imbalanced datasets for retail credit risk assessment. TEM JOURNAL-Technology, Education, Management, Informatics, 7(1), 59-73. doi:10.18421/ TEM71-08

Qiuju, Z. (2017). Personal credit scoring model research based on the RF-GA-SVM model. Italian Journal of Pure and Applied Mathematics, (38), 235-242.

Reddy, K. N., \& Ravi, V. (2013). Differential evolution trained kernel principal component WNN and kernel binary quantile regression: Application to banking. Knowledge-Based Systems, 39, 45-56. doi:10.1016/j. knosys.2012.10.003

Sun, C., \& Jiang, M. (2008). Construction and application of GA-SVM model for prsonal credit scoring. Journal of Information \& Computational Science, 5(2), 567-574. doi:10.2495/ameit140271

Tsakonas, A., \& Dounias, G. (2007). Evolving neural-symbolic systems guided by adaptive training schemes: Applications in finance. Applied Artificial Intelligence, 21(7), 681-706. doi:10.1080/08839510701492603

Vukovic, S., Delibasic, B., Uzelac, A., \& Suknovic, M. (2012). A case-based reasoning model that uses preference theory functions for credit scoring. Expert Systems With Applications, 39(9), 8389-8395. doi:10.1016/j.eswa.2012.01.181

Wang, D., Zhang, Z., Bai, R., \& Mao, Y. (2018). A hybrid system with filter approach and multiple population genetic algorithm for feature selection in credit scoring. Journal of Computational and Applied Mathematics, 329, 307-321. doi:10.1016/j.cam.2017.04.036

Wang, J., Hedar, A., Wang, S., \& Ma, J. (2012). Rough set and scatter search metaheuristic based feature selection for credit scoring. Expert Systems With Applications, 39(6), 6123-6128. doi:10.1016/j. eswa.2011.11.011

Zhang, H., He, H., \& Zhang, W. (2018). Classifier selection and clustering with fuzzy assignment in ensemble model for credit scoring. Neurocomputing, 316, 210-221. doi:10.1016/j.neucom.2018.07.070

Zhou, L., Lai, K. K., \& Yu, L. (2009). Credit scoring using support vector machines with direct search for parameters selection. Soft Computing, 13(2), 149-155. doi:10.1007/s00500-008-0305-0 


\section{Ek: Nitel analize dahil edilen çalış̧malar}

\begin{tabular}{|c|c|c|c|c|c|c|c|c|}
\hline 竞 & 青总 & 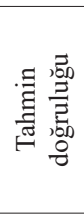 & 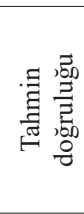 & 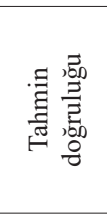 & 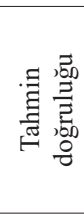 & 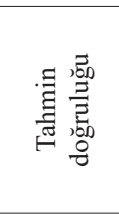 & 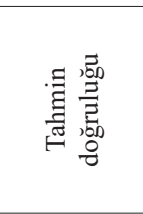 & 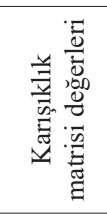 \\
\hline 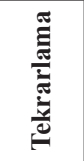 & 总 & 总 & 总 & 总 & ' & 总 & , & \\
\hline 㺼 & 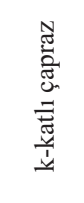 & 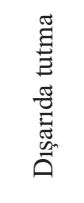 & 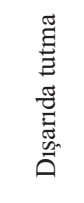 & 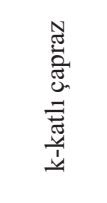 & 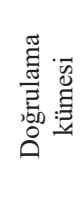 & 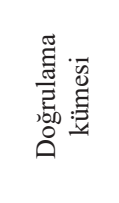 & 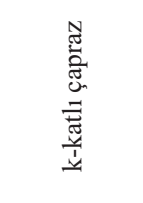 & 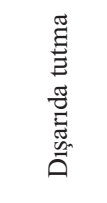 \\
\hline 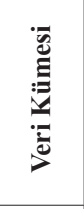 & 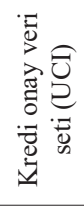 & 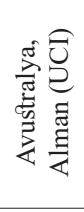 & 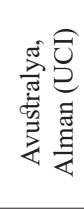 & 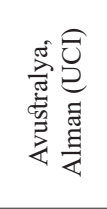 & 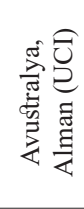 & 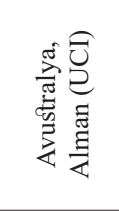 & 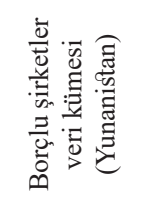 & 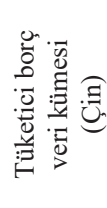 \\
\hline 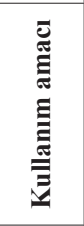 & 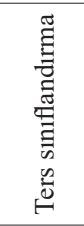 & 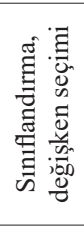 & 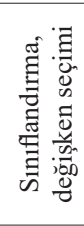 & 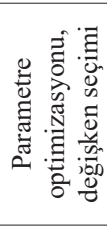 & 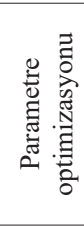 & 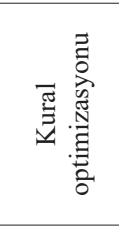 & 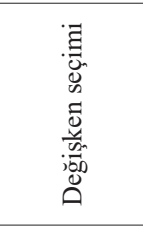 & 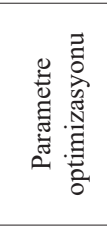 \\
\hline 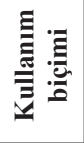 & 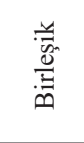 & $\stackrel{\varpi}{\varrho}$ & 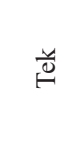 & $\begin{array}{l}\text { 蒙 } \\
\text { 严 }\end{array}$ & $\begin{array}{l}\text { 劳 } \\
\text { 严 }\end{array}$ & 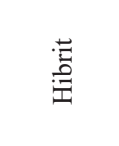 & 泀 & 泀 \\
\hline 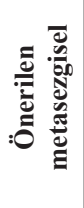 & 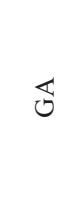 & ثิ & خి & $\mathbb{\mho}$ & Ðิ & 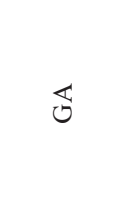 & 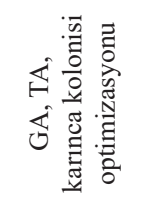 & 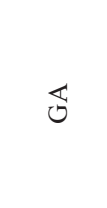 \\
\hline 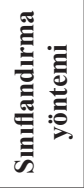 & 艿 & ' & ' & $\sum_{0}^{\sum}$ & 约 & $\ddot{n}$ & $\underset{\nu}{2}$ & $\sum_{0}^{\sum}$ \\
\hline טָ. & 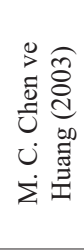 & 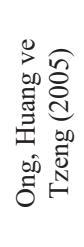 & 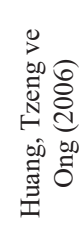 & 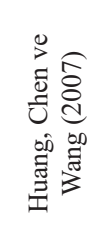 & 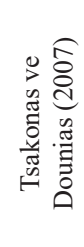 & 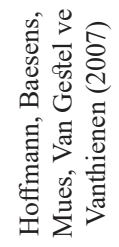 & 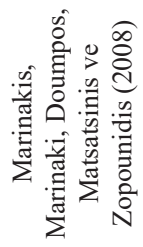 & 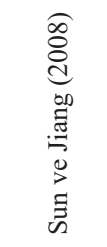 \\
\hline
\end{tabular}


Ek: Nitel analize dahil edilen çalışmalar (dvm.)

\begin{tabular}{|c|c|c|c|c|c|c|c|}
\hline 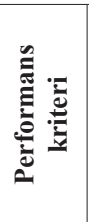 & 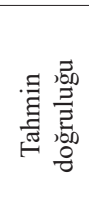 & 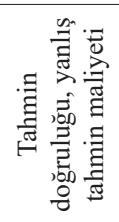 & 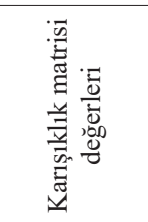 & 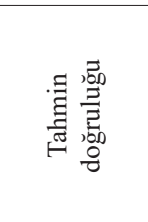 & 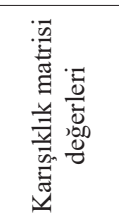 & 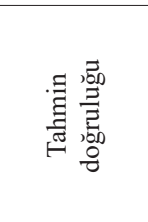 & 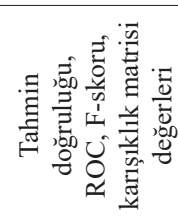 \\
\hline 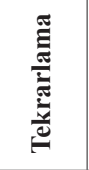 & & & $\begin{array}{l}\overrightarrow{0} \\
\stackrel{D}{\Psi}\end{array}$ & ' & ' & & 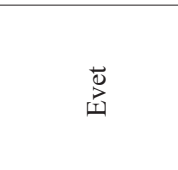 \\
\hline 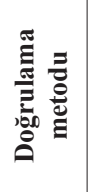 & 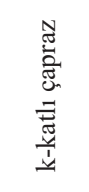 & 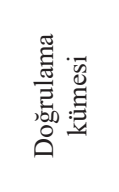 & ' & 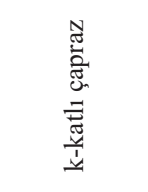 & 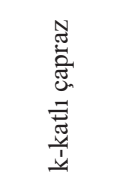 & 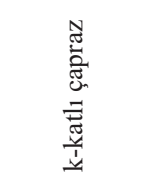 & 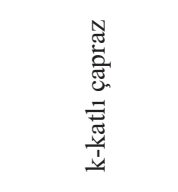 \\
\hline 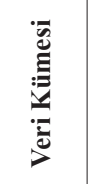 & 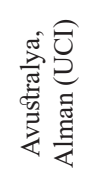 & 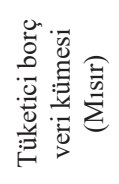 & 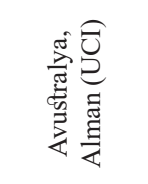 & 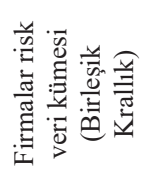 & 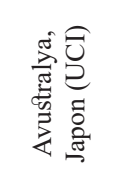 & 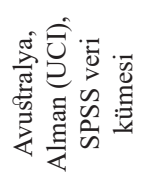 & 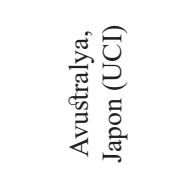 \\
\hline 醇 & 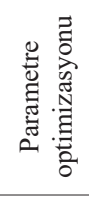 & ' & 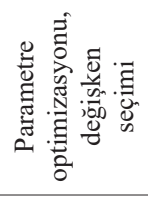 & 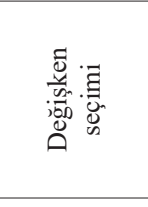 & 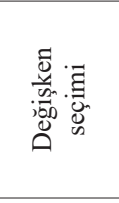 & 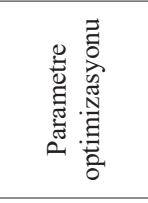 & 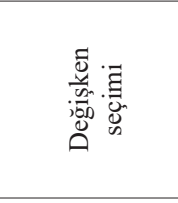 \\
\hline 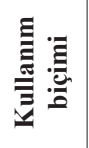 & $\begin{array}{l}\text { 鴶 } \\
\text { 至 }\end{array}$ & $\begin{array}{l}\frac{3}{30} \\
\frac{0}{00} \\
\frac{0}{0} \\
\frac{10}{0}\end{array}$ & 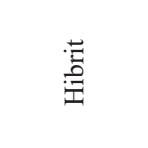 & 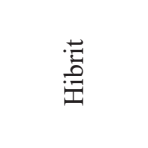 & 蒿 & $\begin{array}{l}\text { 莺 } \\
\text { 严 }\end{array}$ & $\begin{array}{l}\text { 营 } \\
\text { 吾 }\end{array}$ \\
\hline 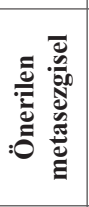 & త্ & કे & 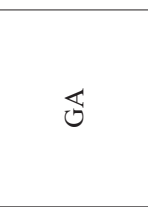 & 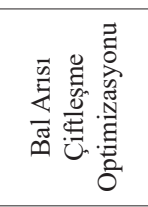 & 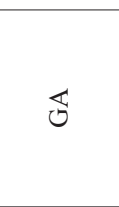 & త & 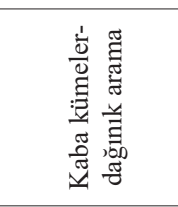 \\
\hline 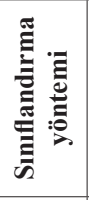 & $\sum_{\text {a }}$ & & $\sum_{\text {a }}$ & $\underset{\Delta}{\Delta}$ & 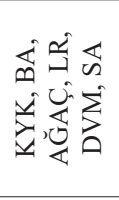 & 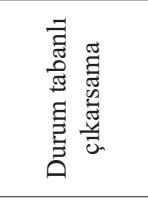 & 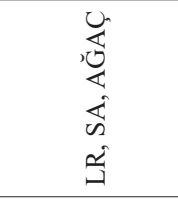 \\
\hline 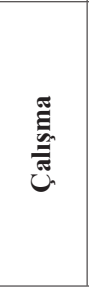 & 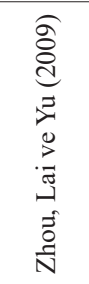 & 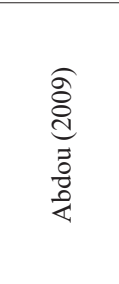 & 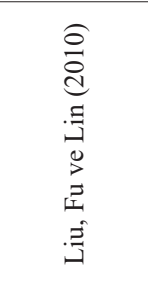 & 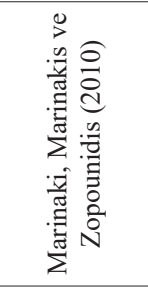 & 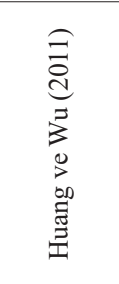 & 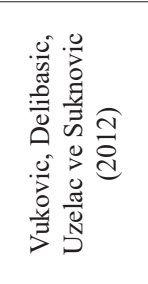 & 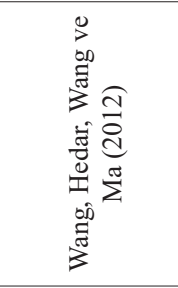 \\
\hline
\end{tabular}




\section{Ek: Nitel analize dahil edilen çalış̧malar (dvm.)}

\begin{tabular}{|c|c|c|c|c|c|c|c|c|}
\hline 童 & 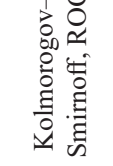 & 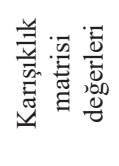 & 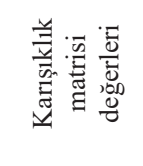 & 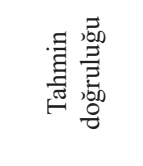 & 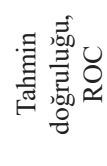 & 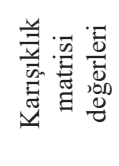 & 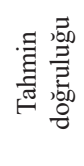 & 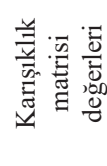 \\
\hline 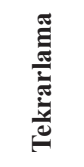 & ' & ' & ' & 岂 & ' & 离 & ( & $\begin{array}{l}\overrightarrow{0} \\
\overrightarrow{\mid \overrightarrow{1}}\end{array}$ \\
\hline 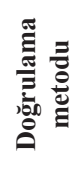 & ' & 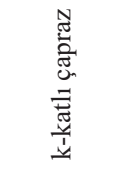 & 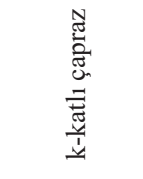 & 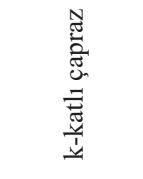 & 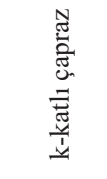 & 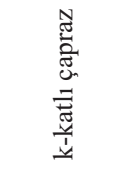 & ' & 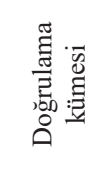 \\
\hline 离 & 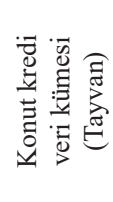 & 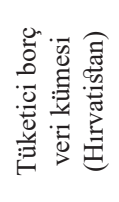 & 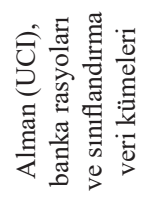 & 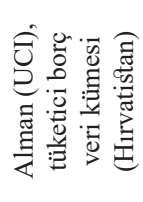 & 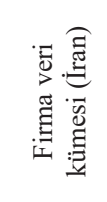 & 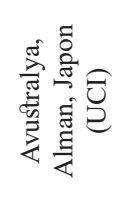 & 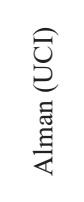 & 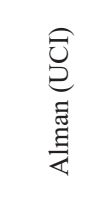 \\
\hline 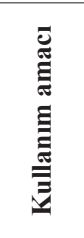 & 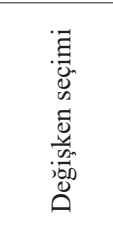 & 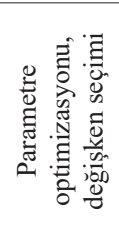 & 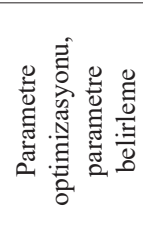 & 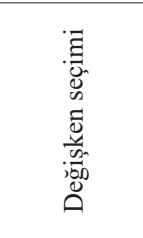 & 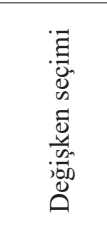 & 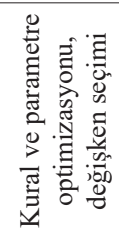 & 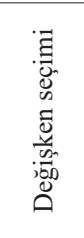 & 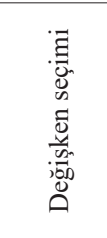 \\
\hline 音 & 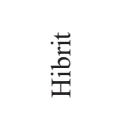 & : & : & : & 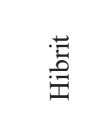 & 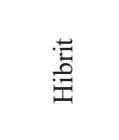 & 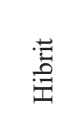 & 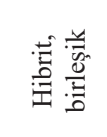 \\
\hline 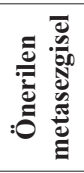 & త్ర & 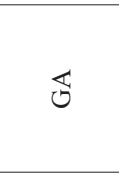 & 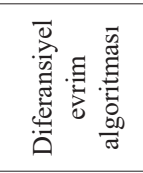 & 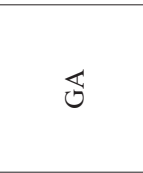 & 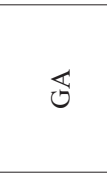 & 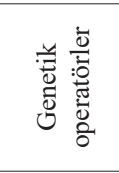 & 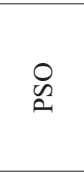 & 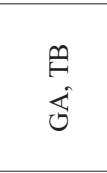 \\
\hline 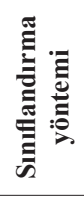 & $\stackrel{a}{a}$ & 出 & 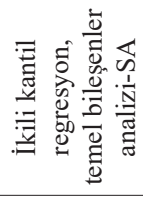 & 岕 & 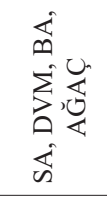 & $\sum_{m}$ & 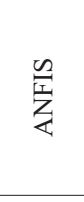 & 志 \\
\hline U⿱艹 & 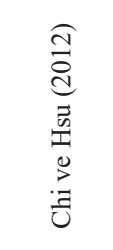 & 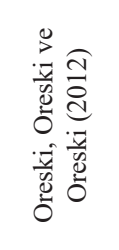 & 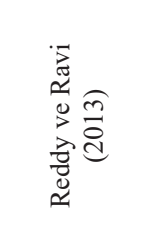 & 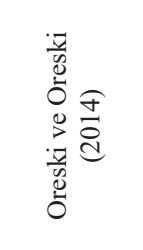 & 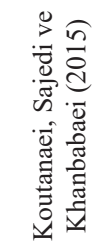 & 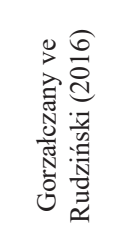 & 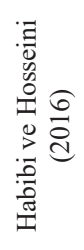 & 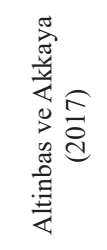 \\
\hline
\end{tabular}




\section{Ek: Nitel analize dahil edilen çalışmalar (dvm.)}

\begin{tabular}{|c|c|c|c|c|c|c|c|}
\hline 党 & 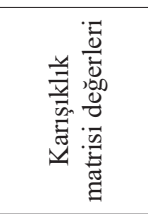 & 青营 & 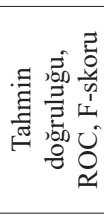 & 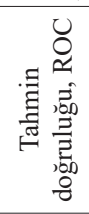 & 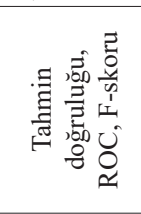 & 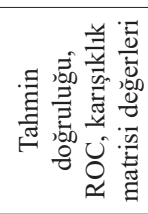 & 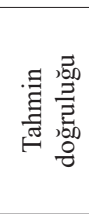 \\
\hline 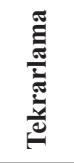 & & & 总 & & & & \\
\hline 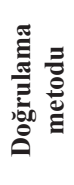 & & 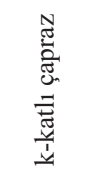 & 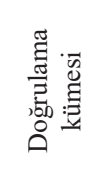 & 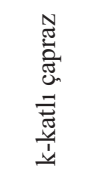 & 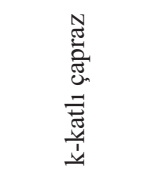 & 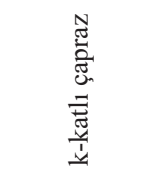 & 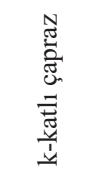 \\
\hline 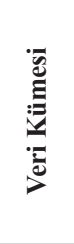 & 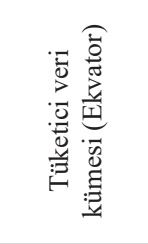 & 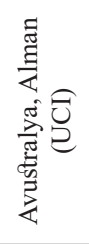 & 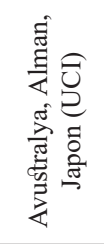 & 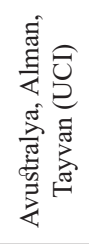 & 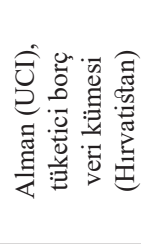 & 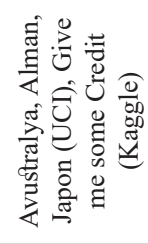 & 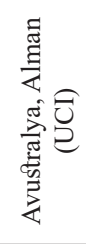 \\
\hline 醇 & 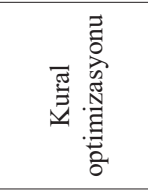 & 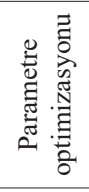 & 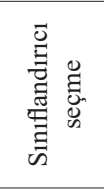 & 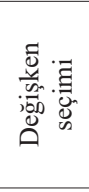 & 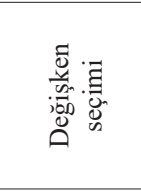 & 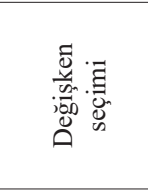 & 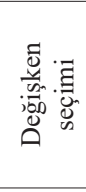 \\
\hline 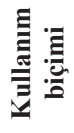 & $\begin{array}{l}\text { 劳 } \\
\text { 吾 }\end{array}$ & 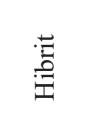 & 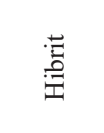 & 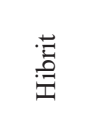 & $\begin{array}{l}\text { 莺 } \\
\text { 至 }\end{array}$ & 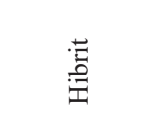 & $\begin{array}{l}\text { 莺 } \\
\text { 严 }\end{array}$ \\
\hline 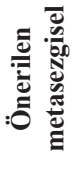 & $\begin{array}{l}0 \\
n \\
n\end{array}$ & త্ర & తુ & త্ర & తુ & $\begin{array}{l}\mathbb{\sharp} \\
\stackrel{\theta}{*}\end{array}$ & త્ \\
\hline 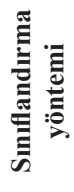 & $\overleftrightarrow{n}$ & 离 & 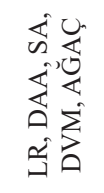 & 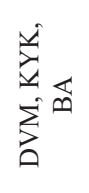 & 岕 & ळ & $\sum_{0}^{\sum}$ \\
\hline 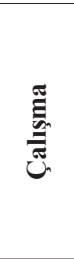 & 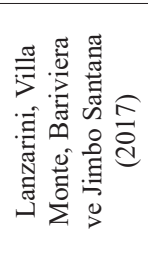 & 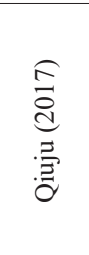 & 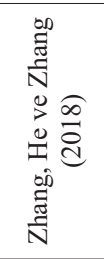 & 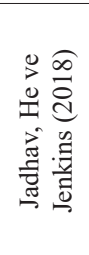 & 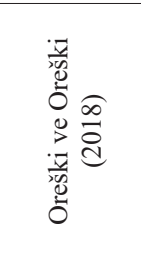 & 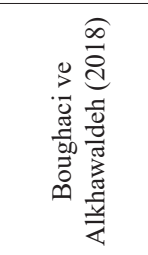 & 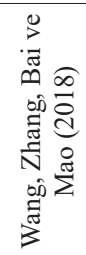 \\
\hline
\end{tabular}

